\title{
CRÓNICA
}

\section{Creación musical chilena}

Cuadro sinóptico de obras de compositores chilenos interpretadas durante el primer semestre

(abril-septiembre, 2011) ${ }^{1}$

\begin{tabular}{|c|c|c|c|c|}
\hline $\begin{array}{l}\text { Nombre del } \\
\text { Compositor }\end{array}$ & Título de la obra & $\begin{array}{l}\text { Fecha de } \\
\text { Interpretación }\end{array}$ & Lugar & Intérpretes \\
\hline \multirow[t]{7}{*}{$\begin{array}{l}\text { Acevedo, } \\
\text { Ricardo }\end{array}$} & Al pie de mi guitarra. & $11 / 05 / 2011$ & $\begin{array}{l}\text { Sala de Conciertos, } \\
\text { Universidad de Tula, Tula, } \\
\text { Rusia. }\end{array}$ & $\begin{array}{l}\text { Ana Álvarez Kemp, soprano; } \\
\text { Patricio Henríquez Ulloa, } \\
\text { guitarra clásica. }\end{array}$ \\
\hline & & $13 / 05 / 2011$ & $\begin{array}{l}\text { IX Festival de Música } \\
\text { Universo del Sonido, } \\
\text { Cantos de Chile, un relato } \\
\text { bicentenario en Europa, } \\
\text { Sala Rachmaninov } \\
\text { del Conservatorio } \\
\text { Tchaikovsky, Moscú. }\end{array}$ & Dúo Álvarez-Henríquez. \\
\hline & & $14 / 05 / 2011$ & $\begin{array}{l}\text { Sala de Conciertos, } \\
\text { Universidad de Saoksky, } \\
\text { Saoksky, Rusia. }\end{array}$ & Dúo Álvarez-Henríquez. \\
\hline & & $15 / 05 / 2011$ & $\begin{array}{l}\text { Sala de Publicaciones, } \\
\text { Universidad de Saoksky, } \\
\text { Saoksky, Rusia. }\end{array}$ & Dúo Álvarez-Henríquez. \\
\hline & & $17 / 05 / 2011$ & $\begin{array}{l}\text { Salón Filarmónico, Teatro } \\
\text { Municipal de Tula, Tula, } \\
\text { Rusia. }\end{array}$ & Dúo Álvarez-Henríquez. \\
\hline & & $24 / 05 / 2011$ & $\begin{array}{l}\text { Sala de Sesiones, División } \\
\text { Euroasiática Organización } \\
\text { Iglesia Adventista del } \\
\text { 7mo. Día Chilena, Moscú. }\end{array}$ & Dúo Álvarez-Henríquez. \\
\hline & & $28 / 05 / 2011$ & $\begin{array}{l}\text { Teatro Moulin D'Ande, } \\
\text { Centro Cultural Moulin } \\
\text { D'Ande, Normandie, } \\
\text { Francia. }\end{array}$ & Dúo Álvarez-Henríquez. \\
\hline Acosta, Víctor & $\begin{array}{l}\text { La joya del Pacifico, vals } \\
\text { (siglo XIX). }\end{array}$ & 03/08/2011 & $\begin{array}{l}\text { Joyas musicales de salón, } \\
\text { Chile, 1850-1950, Sala } \\
\text { Isidora Zegers, Facultad } \\
\text { de Artes, Universidad de } \\
\text { Chile. }\end{array}$ & $\begin{array}{l}\text { Marcela Lillo, piano; Felipe } \\
\text { González, percusión. }\end{array}$ \\
\hline Alba, Antonio & $\begin{array}{l}\text { La japonesa, zamacueca } \\
\text { (siglo XIX). }\end{array}$ & 03/08/2011 & $\begin{array}{l}\text { Joyas musicales de salón, } \\
\text { Chile, 1850-1950, Sala } \\
\text { Isidora Zegers, Facultad } \\
\text { de Artes, Universidad de } \\
\text { Chile. }\end{array}$ & Marcela Lillo, piano. \\
\hline
\end{tabular}

${ }^{1}$ Con $(*)$ se indican estrenos en Chile y con $(* *)$ estrenos en el extranjero.

Revista Musical Chilena, Año LXV, Julio-Diciembre, 2011, N²16, pp. 113-132 


\begin{tabular}{|c|c|c|c|c|}
\hline $\begin{array}{l}\text { Nombre del } \\
\text { Compositor }\end{array}$ & Título de la obra & $\begin{array}{l}\text { Fecha de } \\
\text { Interpretación }\end{array}$ & Lugar & Intérpretes \\
\hline \multirow[t]{3}{*}{ Alexander, Leni } & $\begin{array}{l}3 \text { piezas (El circo) para } \\
\text { piano (1951). }\end{array}$ & $26 / 05 / 2011$ & $\begin{array}{l}\text { Archivo de Música, } \\
\text { Biblioteca Nacional. }\end{array}$ & Ian Bodenhöfer, piano. \\
\hline & $\begin{array}{l}\text { Mandala; ocho piezas para } \\
\text { piano (1962). }\end{array}$ & $26 / 05 / 2011$ & $\begin{array}{l}\text { Archivo de Música, } \\
\text { Biblioteca Nacional. }\end{array}$ & Beatrice Bodenhöfer, piano. \\
\hline & $\begin{array}{l}\text { Paisajes-memoria para } \\
\text { piano (1994). }\end{array}$ & $26 / 05 / 2011$ & $\begin{array}{l}\text { Archivo de Música, } \\
\text { Biblioteca Nacional. }\end{array}$ & $\begin{array}{l}\text { Estela Bellomio, flauta } \\
\text { traversa; Fernanda Ortega, } \\
\text { piano. }\end{array}$ \\
\hline \multirow[t]{10}{*}{$\begin{array}{l}\text { Allende, Pedro } \\
\text { Humberto }\end{array}$} & $\begin{array}{l}\text { La voz de las calles, poema } \\
\text { sinfónico (1920) } \\
\text { (reorquestación para } \\
\text { ensamble realizada por } \\
\text { alumnos de } 4^{\circ} \text { año de } \\
\text { orquestación de la cátedra } \\
\text { del prof. Jorge Pepi Alos. }\end{array}$ & $12 / 07 / 2011$ & $\begin{array}{l}\text { Centro Cultural Gabriela } \\
\text { Mistral (GAM). }\end{array}$ & $\begin{array}{l}\text { Ensamble Compañía de } \\
\text { Música Contemporánea, } \\
\text { Carlos Valenzuela Ramos, } \\
\text { director. }\end{array}$ \\
\hline & & $10 / 08 / 2011$ & $\begin{array}{l}\text { Sala Isidora Zegers, } \\
\text { Facultad de Artes, } \\
\text { Universidad de Chile. }\end{array}$ & $\begin{array}{l}\text { Ensamble Compañía de } \\
\text { Música Contemporánea. }\end{array}$ \\
\hline & $\begin{array}{l}\text { Dos tonadas para piano } \\
(1922) \text {. }\end{array}$ & $10 / 08 / 2011$ & $\begin{array}{l}\text { Sala Isidora Zegers, } \\
\text { Facultad de Artes, } \\
\text { Universidad de Chile. }\end{array}$ & Virna Osses, piano. \\
\hline & $\begin{array}{l}\text { Tres canciones (A las nubes; } \\
\text { Cuando baja la nieve, El } \\
\text { surtidor) para voz y piano } \\
(1926) \text {. }\end{array}$ & $10 / 08 / 2011$ & $\begin{array}{l}\text { Sala Isidora Zegers, } \\
\text { Facultad de Artes, } \\
\text { Universidad de Chile. }\end{array}$ & $\begin{array}{l}\text { Yeanethe Munzenmayer } \\
\text { (soprano), David Inzunza } \\
\text { (piano). }\end{array}$ \\
\hline & $\begin{array}{l}\text { Estudios } 1,2 \text { y } 4 \text { (Nueve } \\
\text { estudios) para piano (1920- } \\
\text { 1936). }\end{array}$ & $10 / 08 / 2011$ & $\begin{array}{l}\text { Sala Isidora Zegers, } \\
\text { Facultad de Artes, } \\
\text { Universidad de Chile. }\end{array}$ & David Inzunza, piano. \\
\hline & $\begin{array}{l}\text { Estudio 3, 5, y } 6 \text { (Nueve } \\
\text { estudios) para piano (1920- } \\
\text { 1936). }\end{array}$ & $10 / 08 / 2011$ & $\begin{array}{l}\text { Sala Isidora Zegers, } \\
\text { Facultad de Artes, } \\
\text { Universidad de Chile. }\end{array}$ & Patricia Castro, piano. \\
\hline & $\begin{array}{l}\text { Estudios } 7,8 \text { y } 9 \text { (Nueve } \\
\text { estudios) para piano (1920- } \\
\text { 1936). }\end{array}$ & $10 / 08 / 2011$ & $\begin{array}{l}\text { Sala Isidora Zegers, } \\
\text { Facultad de Artes, } \\
\text { Universidad de Chile. }\end{array}$ & Kenya Godoy, piano. \\
\hline & $\begin{array}{l}\text { Estudio } \mathrm{N}^{\circ} 7 \text { (Nueve } \\
\text { estudios) (1920-1936). }\end{array}$ & 29/08/2011 & $\begin{array}{l}\text { Sala América, Biblioteca } \\
\text { Nacional. }\end{array}$ & José Contreras, piano. \\
\hline & $\begin{array}{l}\text { Estudios } \mathrm{N}^{\circ} 1 \text { y N } \mathrm{N}^{\circ} 4 \text { (Nueve } \\
\text { estudios) para piano (1920- } \\
\text { 1936). }\end{array}$ & $05 / 09 / 2011$ & $\begin{array}{l}\text { Sala América, Biblioteca } \\
\text { Nacional. }\end{array}$ & Giselle Moraga, piano. \\
\hline & $\begin{array}{l}\text { Tonada } \mathrm{N}^{0} \text { VIII para piano } \\
\text { (1918-1929). }\end{array}$ & 12/09/2011 & $\begin{array}{l}\text { Sala América, Biblioteca } \\
\text { Nacional }\end{array}$ & Daniela Saavedra, piano. \\
\hline $\begin{array}{l}\text { Allende Blin, } \\
\text { Juan }\end{array}$ & $\begin{array}{l}\text { Testamento de Pablo Neruda } \\
\text { para conjunto (1982). }\end{array}$ & $10 / 08 / 2011$ & $\begin{array}{l}\text { Sala Isidora Zegers, } \\
\text { Facultad de Artes, } \\
\text { Universidad de Chile. }\end{array}$ & $\begin{array}{l}\text { Ensamble Taller de Música } \\
\text { Contemporánea, Pablo } \\
\text { Aranda, director. }\end{array}$ \\
\hline Anda, A. de & $\begin{array}{l}\text { Por quién lloras, pas de } \\
\text { quatre (Barn Dance) (siglo } \\
\text { XIX). }\end{array}$ & 03/08/2011 & $\begin{array}{l}\text { Joyas musicales de salón, } \\
\text { Chile, 1850-1950, Sala } \\
\text { Isidora Zegers, Facultad de } \\
\text { Artes, Universidad de Chile. }\end{array}$ & Marcela Lillo, piano. \\
\hline
\end{tabular}




\begin{tabular}{|c|c|c|c|c|}
\hline $\begin{array}{l}\text { Nombre del } \\
\text { Compositor }\end{array}$ & Título de la obra & $\begin{array}{l}\text { Fecha de } \\
\text { Interpretación }\end{array}$ & Lugar & Intérpretes \\
\hline Anónimo & $\begin{array}{l}\text { Debajo de un limón verde, } \\
\text { zamacueca popular } \\
\text { (siglo XIX). }\end{array}$ & 03/08/2011 & $\begin{array}{l}\text { Joyas musicales de salón, } \\
\text { Chile, 1850-1950, Sala } \\
\text { Isidora Zegers, Facultad } \\
\text { de Artes, Universidad de } \\
\text { Chile. }\end{array}$ & Marcela Lillo, piano. \\
\hline \multirow[t]{2}{*}{ Bianchi, Vicente } & $\begin{array}{l}\text { Romance de los Carrera } \\
\text { (1956). } \\
\text { Canto a Bernardo O'Higgins } \\
\text { (Pablo Neruda) (1956). }\end{array}$ & $13 / 05 / 2011$ & $\begin{array}{l}\text { IX Festival de Música } \\
\text { Universo del Sonido, } \\
\text { Cantos de Chile, un relato } \\
\text { bicentenario en Europa, } \\
\text { Sala Rachmaninov } \\
\text { del Conservatorio } \\
\text { Tchaikovsky, Moscú. }\end{array}$ & $\begin{array}{l}\text { Dúo Álvarez-Henríquez: } \\
\text { Ana Álvarez Kemp, soprano; } \\
\text { Patricio Henríquez Ulloa, } \\
\text { guitarra clásica. }\end{array}$ \\
\hline & & $28 / 05 / 2011$ & $\begin{array}{l}\text { Teatro Moulin D'Ande, } \\
\text { Centro Cultural Moulin } \\
\text { D'Ande, Francia. }\end{array}$ & Dúo Álvarez-Henríquez. \\
\hline
\end{tabular}

\begin{tabular}{|c|c|c|c|c|}
\hline $\begin{array}{l}\text { Bisquertt, } \\
\text { Próspero }\end{array}$ & Balada (1928) para piano. & $22 / 08 / 2011$ & $\begin{array}{l}\text { Sala América, Biblioteca } \\
\text { Nacional. }\end{array}$ & Benjamín Vidal, piano. \\
\hline \multirow[t]{2}{*}{ Brncic, Gabriel } & $\begin{array}{l}\text { Quodlibet IV (1968) para } \\
\text { acordeón y cinta. }\end{array}$ & $18 / 06 / 2011$ & $\begin{array}{l}\text { Festival Internacional, "La } \\
\text { música en el Di Tella", } \\
\text { Centro Cultural Borges, } \\
\text { Argentina. }\end{array}$ & Marcelo Delgado, acordeón. \\
\hline & $\begin{array}{l}\text { ¡Volveremos a las } \\
\text { montañas!... (1968) para } \\
\text { orquesta sinfónica. }\end{array}$ & $24 / 06 / 2011$ & $\begin{array}{l}\text { Festival Internacional "La } \\
\text { música en el Di Tella", } \\
\text { Centro Cultural Borges, } \\
\text { Buenos Aires, Argentina. }\end{array}$ & $\begin{array}{l}\text { Orquesta Sinfónica Nacional, } \\
\text { Jorge Sarmientos, director. }\end{array}$ \\
\hline Bührle, Arturo & $\begin{array}{l}\text { Malta blanca, galopa (siglo } \\
\text { XIX). }\end{array}$ & 03/08/2011 & $\begin{array}{l}\text { Joyas musicales de salón, } \\
\text { Chile, 1850-1950, Sala } \\
\text { Isidora Zegers, Facultad } \\
\text { de Artes, Universidad de } \\
\text { Chile. }\end{array}$ & Marcela Lillo, piano. \\
\hline \multirow[t]{3}{*}{$\begin{array}{l}\text { Cáceres, } \\
\text { Eduardo }\end{array}$} & $\begin{array}{l}\text { Fantasíca araucánica para } \\
\text { piano (1984). }\end{array}$ & $27 / 04 / 2011$ & $\begin{array}{l}\text { Lanzamiento CD "Azul } \\
\text { y otros puertos", Sala } \\
\text { Isidora Zegers, Facultad } \\
\text { de Artes, Universidad de } \\
\text { Chile. }\end{array}$ & Patricia Castro, piano. \\
\hline & $\begin{array}{l}\text { Cantos ceremoniales para } \\
\text { aprendiz de machi }(2004) \\
\text { para coro femenino. }\end{array}$ & $27 / 04 / 2011$ & $\begin{array}{l}\text { Lanzamiento CD “Azul } \\
\text { y otros puertos”, Sala } \\
\text { Isidora Zegers, Facultad } \\
\text { de Artes, Universidad de } \\
\text { Chile. }\end{array}$ & $\begin{array}{l}\text { Coro Femenino de Cámara } \\
\text { de la Pontificia Universidad } \\
\text { Católica de Valparaíso } \\
\text { (PUCV), Boris Alvarado, } \\
\text { director. }\end{array}$ \\
\hline & & $24 / 06 / 2011$ & $\begin{array}{l}\text { Exposición "Ecos } \\
\text { imaginarios de un } \\
\text { origen", Colección } \\
\text { Universidad Católica } \\
\text { de Temuco, Centro } \\
\text { de Extensión en } \\
\text { Identidad y Patrimonio, } \\
\text { Departamento de } \\
\text { Ciudadanía y Cultura, } \\
\text { Consejo Nacional de la } \\
\text { Cultura y las Artes. }\end{array}$ & $\begin{array}{l}\text { Coro Femenino de Cámara } \\
\text { de la PUCV, Boris Alvarado, } \\
\text { director. }\end{array}$ \\
\hline
\end{tabular}




\begin{tabular}{|c|c|c|c|c|}
\hline $\begin{array}{l}\text { Nombre del } \\
\text { Compositor }\end{array}$ & Título de la obra & $\begin{array}{l}\text { Fecha de } \\
\text { Interpretación }\end{array}$ & Lugar & Intérpretes \\
\hline & & $\begin{array}{l}24 / 06 / 2011- \\
28 / 08 / 2011\end{array}$ & $\begin{array}{l}\text { Exposición permanente } \\
\text { de instalación con obras } \\
\text { de Cantos ceremoniales } \\
\text { para aprendiz de machi”, } \\
\text { Universidad Católica de } \\
\text { Temuco. }\end{array}$ & $\begin{array}{l}\text { Coro Femenino de Cámara } \\
\text { de la PUCV, Boris Alvarado, } \\
\text { director. }\end{array}$ \\
\hline & & 08/07/2011 & $\begin{array}{l}\text { Lanzamiento CD “Azul y } \\
\text { otros puertos”, Edificio } \\
\text { Cousiño DUOC UC, } \\
\text { Teatro del Centro de } \\
\text { Gestión del Turismo, } \\
\text { Patrimonio y Cultura, } \\
\text { Valparaíso. }\end{array}$ & $\begin{array}{l}\text { Coro Femenino de Cámara } \\
\text { de la PUCV, Boris Alvarado, } \\
\text { director. }\end{array}$ \\
\hline $\begin{array}{l}\text { Cantón, } \\
\text { Edgardo }\end{array}$ & $\begin{array}{l}\text { Concierto Ahad para } \\
\text { percusión y orquesta. }\end{array}$ & $12,13 / 08 / 2011$ & $\begin{array}{l}\text { Teatro Universidad de } \\
\text { Chile. }\end{array}$ & $\begin{array}{l}\text { Orquesta Sinfónica de Chile, } \\
\text { Andrew Gourlay, director } \\
\text { invitado, Juan Coderch, } \\
\text { percusión. }\end{array}$ \\
\hline $\begin{array}{l}\text { Cantón Edgardo, } \\
\text { Leonardo } \\
\text { Cendoyya, } \\
\text { Rolando } \\
\text { Cori, Juan } \\
\text { Pablo Aguayo } \\
\text { y Cristián } \\
\text { Errandonea }\end{array}$ & $\begin{array}{l}\text { Tierra de Larry (2010) para } \\
\text { conjunto instrumental y } \\
\text { medios electrónicos. }\end{array}$ & $17 / 05 / 2011$ & $\begin{array}{l}\text { Ciclo música del siglo XX } \\
\text { y XXI, Centro Cultural } \\
\text { Gabriela Mistral (GAM). }\end{array}$ & $\begin{array}{l}\text { Ensamble Tierra de Larry: } \\
\text { Rolando Cori (guitarra y } \\
\text { laptop), Leonardo Cendoyya } \\
\text { (sintetizador y laptop), } \\
\text { Edgardo Cantón (piano y } \\
\text { laptop), Juan Pablo Aguayo } \\
\text { (flauta traversa y piccolo), } \\
\text { Cristián Errandonea } \\
\text { (contrabajo). }\end{array}$ \\
\hline \multirow[t]{2}{*}{ Carmona, Óscar } & $\begin{array}{l}\text { Art of improvisation IV } \\
\text { (2011), live cinema, } \\
\text { remix, piano, live } \\
\text { electronics, samplers, } \\
\text { voces en off. }\end{array}$ & $31 / 05 / 2011$ & $\begin{array}{l}\text { Ciclo de música del } \\
\text { siglo XX y XXI, Centro } \\
\text { Cultural Gabriela Mistral } \\
\text { (GAM). }\end{array}$ & $\begin{array}{l}\text { Concierto "Gráficas digitales, } \\
\text { danza y electrónica en tiempo } \\
\text { real", Óscar Carmona, piano y } \\
\text { electrónica. }\end{array}$ \\
\hline & $\begin{array}{l}\text { Jeux }(2005) \text { para fagot } \\
\text { y piano. }\end{array}$ & 07/09/2011 & $\begin{array}{l}\text { Ciclo de música chilena } \\
\text { y latinoamericana, Sala } \\
\text { Isidora Zegers, Facultad } \\
\text { de Artes de la Universidad } \\
\text { de Chile. }\end{array}$ & $\begin{array}{l}\text { Jorge Espinoza F., fagot; } \\
\text { Patricia Castro, piano. }\end{array}$ \\
\hline $\begin{array}{l}\text { Carnicer, } \\
\text { Ramón }\end{array}$ & $\begin{array}{l}\text { Himno Nacional de Chile } \\
\text { (1827). }\end{array}$ & 03/08/2011 & $\begin{array}{l}\text { Joyas musicales de salón, } \\
\text { Chile, 1850-1950, Sala } \\
\text { Isidora Zegers, Facultad } \\
\text { de Artes, Universidad de } \\
\text { Chile. }\end{array}$ & Marcela Lillo, piano. \\
\hline $\begin{array}{l}\text { Carrera, } \\
\text { Armando }\end{array}$ & $\begin{array}{l}\text { Antofagasta, vals Boston } \\
\text { (ca. 1916). }\end{array}$ & 03/08/2011 & $\begin{array}{l}\text { Joyas musicales de salón, } \\
\text { Chile, 1850-1950, Sala } \\
\text { Isidora Zegers, Facultad } \\
\text { de Artes, Universidad de } \\
\text { Chile. }\end{array}$ & $\begin{array}{l}\text { Marcela Lillo, piano; Felipe } \\
\text { González, percusión. }\end{array}$ \\
\hline $\begin{array}{l}\text { Carvallo, } \\
\text { Antonio }\end{array}$ & $\begin{array}{l}\text { Sub }(2005) \text { para sonidos } \\
\text { electrónicos y danza. }\end{array}$ & $31 / 05 / 2011$ & $\begin{array}{l}\text { Ciclo de música del } \\
\text { siglo XX y XXI, Centro } \\
\text { Cultural Gabriela Mistral } \\
\text { (GAM). }\end{array}$ & $\begin{array}{l}\text { Concierto "Gráficas digitales, } \\
\text { danza y electrónica en tiempo } \\
\text { real", Lilian Pizarro, danza. }\end{array}$ \\
\hline
\end{tabular}




\begin{tabular}{|c|c|c|c|c|}
\hline $\begin{array}{l}\text { Nombre del } \\
\text { Compositor }\end{array}$ & Título de la obra & $\begin{array}{l}\text { Fecha de } \\
\text { Interpretación }\end{array}$ & Lugar & Intérpretes \\
\hline $\begin{array}{l}\text { Casanovas, } \\
\text { Augusto }\end{array}$ & $\begin{array}{l}\text { El temporal del Cabo de } \\
\text { Hornos, vals brillante } \\
(1863) \text {. }\end{array}$ & 03/08/2011 & $\begin{array}{l}\text { Joyas musicales de salón, } \\
\text { Chile, 1850-1950, Sala } \\
\text { Isidora Zegers, Facultad } \\
\text { de Artes, Universidad de } \\
\text { Chile. }\end{array}$ & Marcela Lillo, piano. \\
\hline
\end{tabular}

Colomer, Rafael 18 de Septiembre, marcha 03/08/2011 (siglo XIX).

Joyas musicales de salón, Marcela Lillo, piano.

Chile, 1850-1950, Sala

Isidora Zegers, Facultad

de Artes, Universidad de

Chile

\begin{tabular}{lllll}
\hline Cortés, Renán & $\begin{array}{l}\text { **Rito }(2004-2005) \text { para } \\
\text { cuarteto de guitarras. }\end{array}$ & $14 / 05 / 2011$ & $\begin{array}{l}\text { Festival de Guitarra de } \\
\text { Lausanne, Suiza. }\end{array}$ & $\begin{array}{l}\text { Cuarteto de Guitarras de } \\
\text { Chile: Luis Orlandini, } \\
\text { Rodrigo Guzmán, Sebastián } \\
\text { Montes y Luis Mancilla. }\end{array}$ \\
\hline Cotapos, Acario & $\begin{array}{l}\text { Tres preludios (1925) para } \\
\text { orquesta de cámara. }\end{array}$ & $14 / 04 / 2011$ & $\begin{array}{l}\text { Aula Magna de la } \\
\text { Universidad Austral de } \\
\text { Chile. }\end{array}$ & $\begin{array}{l}\text { Orquesta de Cámara de } \\
\text { Valdivia, Víctor Hugo Toro, } \\
\text { director invitado. }\end{array}$ \\
\hline Délano, Pablo & $\begin{array}{l}\text { Espiral (Dos canciones) } \\
\text { (1968), texto Alicia } \\
\text { Morel. } \\
\text { Me tuviste (Canciones }\end{array}$ & $11 / 05 / 2011$ & $\begin{array}{l}\text { Sala de Conciertos, } \\
\text { Universidad de Tula, Tula, Ana Álvarez Kemp, soprano; } \\
\text { Rusia. }\end{array}$ & $\begin{array}{l}\text { Patricio Henríquez Ulloa, } \\
\text { guitarra clásica. }\end{array}$
\end{tabular}

de cuna) (2002), texto

homónimo de Gabriela

Mistral.

$13 / 05 / 2011$

IX Festival de Música

Universo del Sonido,

Dúo Álvarez-Henríquez

Cantos de Chile, un relato

bicentenario en Europa,

Sala Rachmaninov

del Conservatorio

Tchaikovsky, Moscú.

14/05/2011 Sala de Conciertos, Dúo Álvarez-Henríquez.

Universidad de Saoksky,

Saoksky, Rusia.

15/05/2011 Sala de Publicaciones, Dúo Álvarez-Henríquez.

Universidad de Saoksky,

Saoksky, Rusia.

17/05/2011 Salón Filarmónico, Teatro Dúo Álvarez-Henríquez. Municipal de Tula, Tula,

Rusia.

24/05/2011 Sala de Sesiones, División Dúo Álvarez-Henríquez. Euroasiática Organización

Iglesia Adventista del

7mo. Día Chilena, Moscú.

28/05/2011 Teatro Moulin D’Ande, Dúo Álvarez-Henríquez.

Centro Cultural Moulin

D'Ande, Normandie,

Francia. 


\begin{tabular}{|c|c|c|c|c|}
\hline $\begin{array}{l}\text { Nombre del } \\
\text { Compositor }\end{array}$ & Título de la obra & $\begin{array}{l}\text { Fecha de } \\
\text { Interpretación }\end{array}$ & Lugar & Intérpretes \\
\hline \multirow[t]{2}{*}{ Díaz, Rafael } & $\begin{array}{l}\text { * Rio Cisnes, vuelo a casa } \\
\text { (2011) para guitarra. }\end{array}$ & $19 / 05 / 2011$ & $\begin{array}{l}\text { Centro Cultural Gabriela } \\
\text { Mistral (GAM). }\end{array}$ & Alejandro Peralta, guitarra. \\
\hline & $\begin{array}{l}\text { Viajan los lugares a las } \\
\text { horas propicias (2009) para } \\
\text { conjunto. }\end{array}$ & $24 / 05 / 2011$ & $\begin{array}{l}\text { Centro Cultural Gabriela } \\
\text { Mistral (GAM). }\end{array}$ & $\begin{array}{l}\text { Ensamble Compañía de } \\
\text { Música Contemporánea, } \\
\text { Carlos Valenzuela Ramos, } \\
\text { director. }\end{array}$ \\
\hline $\begin{array}{l}\text { Domínguez, } \\
\text { José Luis }\end{array}$ & $\begin{array}{l}\text { El zorro }(2009) \text { para } \\
\text { orquesta. }\end{array}$ & $11,12 / 03 / 2011$ & $\begin{array}{l}\text { Temporada Oficial de } \\
\text { Conciertos 2011, Centro } \\
\text { de Extensión Artística y } \\
\text { Cultural, Universidad de } \\
\text { Chile. }\end{array}$ & $\begin{array}{l}\text { Orquesta Filarmónica } \\
\text { de Santiago, José Luis } \\
\text { Domínguez, director. }\end{array}$ \\
\hline \multirow[t]{2}{*}{$\begin{array}{l}\text { Errázuriz, } \\
\text { Sebastián }\end{array}$} & $\begin{array}{l}\text { Siete proposiciones sensibles } \\
\text { pero sensatas (2004) para } \\
\text { orquesta. }\end{array}$ & $10 / 07 / 2011$ & $\begin{array}{l}\text { Orquesta de Cámara de } \\
\text { Valdivia. }\end{array}$ & $\begin{array}{l}\text { Eduardo Browne, director } \\
\text { invitado. }\end{array}$ \\
\hline & $\begin{array}{l}\text { Fuga en tango }(\text { Tres } \\
\text { movimientos) }(1999) \text { para } \\
\text { conjunto. }\end{array}$ & $04 / 09 / 2011$ & $\begin{array}{l}\text { Auditorio de la } \\
\text { Universidad de los Andes, } \\
\text { San Carlos de Apoquindo, } \\
\text { Santiago. }\end{array}$ & $\begin{array}{l}\text { Camerata Universidad de } \\
\text { los Andes, Eduardo Browne, } \\
\text { director. }\end{array}$ \\
\hline \multirow[t]{2}{*}{$\begin{array}{l}\text { Falabella, } \\
\text { Roberto }\end{array}$} & $\begin{array}{l}\text { Divertimento } \mathrm{N}^{\circ} 1 \text { (1956) } \\
\text { para orquesta de cámara. }\end{array}$ & $30 / 06 / 2011$ & $\begin{array}{l}\text { Orquesta de Cámara de } \\
\text { Valdivia. }\end{array}$ & Cristóbal Urrutia, director. \\
\hline & & $18 / 07 / 2011$ & $\begin{array}{l}\text { Orquesta de Cámara de } \\
\text { Valdivia. }\end{array}$ & Cristóbal Urrutia, director. \\
\hline \multirow[t]{3}{*}{$\begin{array}{l}\text { Farías C.. } \\
\text { Javier }\end{array}$} & $\begin{array}{l}\text { Trastocada }(2007) \text { para } \\
\text { dúo de guitarras. }\end{array}$ & $22 / 06 / 2011$ & $\begin{array}{l}\text { Ciclo de música chilena } \\
\text { y latinoamericana, Sala } \\
\text { Isidora Zegers, Facultad } \\
\text { de Artes de la Universidad } \\
\text { de Chile. }\end{array}$ & Dúo Orellana \& Orlandini. \\
\hline & $\begin{array}{l}* \text { Concierto }(2000) \\
\text { para cuatro guitarras y } \\
\text { orquesta }\end{array}$ & $07 / 08 / 2011$ & $\begin{array}{l}\text { Auditorio de la } \\
\text { Universidad de Los } \\
\text { Andes, San Carlos de } \\
\text { Apoquindo, Santiago. }\end{array}$ & $\begin{array}{l}\text { Cuarteto de Guitarras } \\
\text { de Chile; Camerata de la } \\
\text { Universidad de Los Andes, } \\
\text { Eduardo Browne, director. }\end{array}$ \\
\hline & $\begin{array}{l}\text { Concierto para cuatro } \\
\text { guitarras. }\end{array}$ & $07 / 08 / 2011$ & $\begin{array}{l}\text { Auditorio de la } \\
\text { Universidad de los Andes, } \\
\text { San Carlos de Apoquindo, } \\
\text { Santiago. }\end{array}$ & $\begin{array}{l}\text { Ensamble de guitarras de } \\
\text { Chile, Javier Farías, director. }\end{array}$ \\
\hline Ferrari, Andrés & $\begin{array}{l}\text { Inertia léxico cromática } \\
\text { (2011), performance } \\
\text { danza-audiovisual, para } \\
\text { dos bailarinas, electrónica } \\
\text { e imágenes interactivas. }\end{array}$ & $31 / 05 / 2011$ & $\begin{array}{l}\text { Ciclo de música del } \\
\text { siglo XX y XXI, Centro } \\
\text { Cultural Gabriela Mistral } \\
(\mathrm{GAM}) \text {. }\end{array}$ & $\begin{array}{l}\text { Concierto "Gráficas digitales, } \\
\text { danza y electrónica en tiempo } \\
\text { real", Daniela Rojas y Nelly } \\
\text { Todorova, danza. }\end{array}$ \\
\hline \multirow[t]{2}{*}{$\begin{array}{l}\text { García, } \\
\text { Fernando }\end{array}$} & $\begin{array}{l}\text { Sabelliades a Ruiseñor Rojo } \\
\text { (texto Andrés Sabella) } \\
\text { (1972) para voz y piano. }\end{array}$ & $08 / 06 / 2011$ & $\begin{array}{l}\text { Sala Isidora Zegers, } \\
\text { Facultad de Artes, } \\
\text { Universidad de Chile. }\end{array}$ & $\begin{array}{l}\text { Cecilia Barrientos, soprano; } \\
\text { David Inzunza, piano. }\end{array}$ \\
\hline & $\begin{array}{l}\text { El espejo de agua (texto } \\
\text { Vicente Huidobro) } \\
\text { (1983), para voz y piano. }\end{array}$ & 08/06/2011 & $\begin{array}{l}\text { Sala Isidora Zegers, } \\
\text { Facultad de Artes, } \\
\text { Universidad de Chile. }\end{array}$ & $\begin{array}{l}\text { David Gaez, bajo; David } \\
\text { Inzunza, piano. }\end{array}$ \\
\hline
\end{tabular}




\begin{tabular}{|c|c|c|c|c|}
\hline $\begin{array}{l}\text { Nombre del } \\
\text { Compositor }\end{array}$ & Título de la obra & $\begin{array}{l}\text { Fecha de } \\
\text { Interpretación }\end{array}$ & Lugar & Intérpretes \\
\hline \multirow[t]{7}{*}{$\begin{array}{l}\text { García, } \\
\text { Fernando }\end{array}$} & \multirow[t]{2}{*}{$\begin{array}{l}\text { Tres piezas breves (1995) } \\
\text { para guitarra. }\end{array}$} & 08/06/2011 & $\begin{array}{l}\text { Sala Isidora Zegers, } \\
\text { Facultad de Artes, } \\
\text { Universidad de Chile. }\end{array}$ & Eduardo Padilla, guitarra. \\
\hline & & 03/08/2011 & $\begin{array}{l}\text { Biblioteca Pública } \\
\text { Municipal de Quinta } \\
\text { Normal. }\end{array}$ & Luis Orlandini, guitarra. \\
\hline & $\begin{array}{l}\text { Celebración (2011), } \\
\text { dedicada al Ensemble } \\
\text { Bartok. }\end{array}$ & 08/06/2011 & $\begin{array}{l}\text { Sala Isidora Zegers, } \\
\text { Facultad de Artes, } \\
\text { Universidad de Chile. }\end{array}$ & $\begin{array}{l}\text { Ensemble Bartok, Valene } \\
\text { Georges, directora. }\end{array}$ \\
\hline & \multirow[t]{2}{*}{$\begin{array}{l}\text { *Mirando en el microscopio } \\
\text { (2011) para flauta traversa } \\
\text { y piano. }\end{array}$} & $02 / 07 / 2011$ & $\begin{array}{l}\text { "Encuentro musical con } \\
\text { el Dúo Bilitis", Escuela de } \\
\text { Arte Sagrada, Olmué. }\end{array}$ & $\begin{array}{l}\text { Dúo Bilitis: Carlos Rojas, flauta } \\
\text { traversa; Alexandra Aubert, } \\
\text { piano. }\end{array}$ \\
\hline & & $12 / 08 / 2011$ & $\begin{array}{l}\text { Teatro Municipal de Viña } \\
\text { del Mar. }\end{array}$ & Dúo Bilitis. \\
\hline & $\begin{array}{l}\text { ** Cuadros sinfónicos } \\
\text { (2011) (dedicado a Hilda } \\
\text { Riveros). }\end{array}$ & $14 / 08 / 2011$ & $\begin{array}{l}\text { X Festival de Orquestas } \\
\text { Juveniles, Sala Principal, } \\
\text { Teatro Municipal de } \\
\text { Santiago. }\end{array}$ & $\begin{array}{l}\text { Orquesta Municipal Juvenil de } \\
\text { Puente Alto, Lorena Vergara, } \\
\text { directora. }\end{array}$ \\
\hline & $\begin{array}{l}\text { Microsuite (2011) para } \\
\text { violín, flauta y guitarra. }\end{array}$ & $31 / 08 / 2011$ & $\begin{array}{l}\text { Sala América, Biblioteca } \\
\text { Nacional. }\end{array}$ & $\begin{array}{l}\text { Daniella Rivera, violín; Paula } \\
\text { Barrientos, flauta; Luis } \\
\text { Mancilla, guitarra. }\end{array}$ \\
\hline $\begin{array}{l}\text { Garrido-Lecca, } \\
\text { Celso }\end{array}$ & $\begin{array}{l}\text { Concierto (1990) para } \\
\text { guitarra y grupos } \\
\text { instrumentales. }\end{array}$ & $25 / 08 / 2011$ & $\begin{array}{l}\text { Festival Interamericano } \\
\text { de las Artes (FIA) 2011, } \\
\text { Teatro de la Universidad } \\
\text { de Puerto Rico, San Juan. }\end{array}$ & $\begin{array}{l}\text { Luis Orlandini, guitarra; } \\
\text { Orquesta Sinfónica de San } \\
\text { Juan Puerto Rico, Maximiano } \\
\text { Valdés, director. }\end{array}$ \\
\hline Goles, José & $\begin{array}{l}\text { El paso del pollo, foxtrot } \\
\text { (siglo XX). }\end{array}$ & 03/08/2011 & $\begin{array}{l}\text { Joyas musicales de salón, } \\
\text { Chile, 1850-1950, Sala } \\
\text { Isidora Zegers, Facultad } \\
\text { de Artes, Universidad de } \\
\text { Chile. }\end{array}$ & $\begin{array}{l}\text { Marcela Lillo, piano; Felipe } \\
\text { González, percusión. }\end{array}$ \\
\hline $\begin{array}{l}\text { Guerra, } \\
\text { Gamaliel }\end{array}$ & $\begin{array}{l}\text { En Mejillones yo tuve un } \\
\text { amor, foxtrot (siglo XX). }\end{array}$ & 03/08/2011 & $\begin{array}{l}\text { Joyas musicales de Salón, } \\
\text { Chile, 1850-1950, Sala } \\
\text { Isidora Zegers, Facultad } \\
\text { de Artes, Universidad de } \\
\text { Chile. }\end{array}$ & $\begin{array}{l}\text { Marcela Lillo, piano; Felipe } \\
\text { González, percusión. }\end{array}$ \\
\hline $\begin{array}{l}\text { Guzmán, } \\
\text { Federico }\end{array}$ & $\begin{array}{l}\text { Zamacueca } \mathrm{N}^{\circ} 3 \\
\text { (siglo XIX). }\end{array}$ & 03/08/2011 & $\begin{array}{l}\text { Joyas musicales de salón, } \\
\text { Chile, 1850-1950, Sala } \\
\text { Isidora Zegers, Facultad } \\
\text { de Artes, Universidad de } \\
\text { Chile }\end{array}$ & Marcela Lillo, piano. \\
\hline Jara, Víctor & $\begin{array}{l}\text { Plegaria a un labrador } \\
\text { (1969). } \\
\text { Cuando voy al trabajo } \\
\text { (1973). }\end{array}$ & $11 / 05 / 2011$ & $\begin{array}{l}\text { Sala de Conciertos, } \\
\text { Universidad de Tula, Tula, } \\
\text { Rusia. }\end{array}$ & $\begin{array}{l}\text { Dúo Álvarez-Henríquez: } \\
\text { Ana Álvarez Kemp, soprano; } \\
\text { Patricio Henríquez Ulloa, } \\
\text { guitarra clásica. }\end{array}$ \\
\hline
\end{tabular}




\begin{tabular}{|c|c|c|c|c|}
\hline $\begin{array}{l}\text { Nombre del } \\
\text { Compositor }\end{array}$ & Título de la obra & $\begin{array}{l}\text { Fecha de } \\
\text { Interpretación }\end{array}$ & Lugar & Intérpretes \\
\hline \multirow[t]{14}{*}{ Jara, Víctor } & & $13 / 05 / 2011$ & $\begin{array}{l}\text { IX Festival de Música } \\
\text { Universo del Sonido, } \\
\text { Cantos de Chile, un relato } \\
\text { bicentenario en Europa, } \\
\text { Sala Rachmaninov } \\
\text { del Conservatorio } \\
\text { Tchaikovsky, Moscú. }\end{array}$ & Dúo Álvarez-Henríquez \\
\hline & & $14 / 05 / 2011$ & $\begin{array}{l}\text { Sala de Conciertos, } \\
\text { Universidad de Saoksky, } \\
\text { Saoksky, Rusia. }\end{array}$ & Dúo Álvarez-Henríquez. \\
\hline & & $15 / 05 / 2011$ & $\begin{array}{l}\text { Sala de Publicaciones, } \\
\text { Universidad de Saoksky, } \\
\text { Saoksky, Rusia. }\end{array}$ & Dúo Álvarez-Henríquez. \\
\hline & & $17 / 05 / 2011$ & $\begin{array}{l}\text { Salón Filarmónico, Teatro } \\
\text { Municipal de Tula, Tula, } \\
\text { Rusia. }\end{array}$ & Dúo Álvarez-Henríquez. \\
\hline & & $24 / 05 / 2011$ & $\begin{array}{l}\text { Sala de Sesiones, División } \\
\text { Euroasiática Organización } \\
\text { Iglesia Adventista del } \\
\text { 7mo. Día Chilena, Moscú. }\end{array}$ & Dúo Álvarez-Henríquez. \\
\hline & & $28 / 05 / 2011$ & $\begin{array}{l}\text { Teatro Moulin D'Ande, } \\
\text { Centro Cultural Moulin } \\
\text { D'Ande, Normandie, } \\
\text { Francia. }\end{array}$ & Dúo Álvarez-Henríquez. \\
\hline & $\begin{array}{l}\text { Luchin (1972), versión } \\
\text { para marimbas. }\end{array}$ & $12 / 06 / 2011$ & $\begin{array}{l}\text { Centro Cultural Gabriela } \\
\text { Mistral (GAM). }\end{array}$ & $\begin{array}{l}\text { Ensamble Compañía de } \\
\text { Música Contemporánea, } \\
\text { Carlos Valenzuela Ramos, } \\
\text { director. }\end{array}$ \\
\hline & $\begin{array}{l}\text { Luchin (1972), versión de } \\
\text { orquesta de jazz. }\end{array}$ & $24 / 07 / 2011$ & $\begin{array}{l}\text { Plaza del Ayuntamiento } \\
\text { de Toledo, España. }\end{array}$ & $\begin{array}{l}\text { Orquesta de Jazz UCV Big } \\
\text { Bang. }\end{array}$ \\
\hline & & $26 / 07 / 2011$ & $\begin{array}{l}\text { Ciclo de Conciertos } \\
\text { Veranos de la Villa de } \\
\text { Madrid, España }\end{array}$ & $\begin{array}{l}\text { Orquesta de Jazz UCV Big- } \\
\text { Bang. }\end{array}$ \\
\hline & $\begin{array}{l}\text { Luchin (1972) (en arreglo } \\
\text { del prof. Mario Baeza } \\
\text { Ciccione). }\end{array}$ & $26 / 07 / 2011$ & $\begin{array}{l}\text { Temporada Oficial de } \\
\text { Conciertos, Universidad } \\
\text { de Chile, Centro Cultural } \\
\text { Gabriela Mistral (GAM). }\end{array}$ & $\begin{array}{l}\text { Patricio Hernández, marimba } \\
\text { y Ensamble Teluriko. }\end{array}$ \\
\hline & $\begin{array}{l}\text { Luchin (1972) versión de } \\
\text { orquesta de jazz. }\end{array}$ & $27 / 07 / 2011$ & $\begin{array}{l}\text { Penelles, Lleida, Plaza } \\
\text { Central, España. }\end{array}$ & $\begin{array}{l}\text { Orquesta de Jazz UCV Big- } \\
\text { Bang. }\end{array}$ \\
\hline & & $28 / 07 / 2011$ & $\begin{array}{l}\text { Teatro Liceu de } \\
\text { Barcelona, España. }\end{array}$ & $\begin{array}{l}\text { Orquesta de Jazz UCV Big- } \\
\text { Bang. }\end{array}$ \\
\hline & & $29 / 07 / 2011$ & $\begin{array}{l}\text { Festival Terrassa d'Stiu, } \\
\text { Plaza Lluis Companys de } \\
\text { Terrassa, España. }\end{array}$ & $\begin{array}{l}\text { Orquesta de Jazz UCV Big- } \\
\text { Bang. }\end{array}$ \\
\hline & & $30 / 07 / 2011$ & $\begin{array}{l}\text { Sede de los Castellers de } \\
\text { Vilafranca, España. }\end{array}$ & $\begin{array}{l}\text { Orquesta de Jazz UCV Big- } \\
\text { Bang. }\end{array}$ \\
\hline
\end{tabular}




\begin{tabular}{|c|c|c|c|c|}
\hline $\begin{array}{l}\text { Nombre del } \\
\text { Compositor }\end{array}$ & Título de la obra & $\begin{array}{l}\text { Fecha de } \\
\text { Interpretación }\end{array}$ & Lugar & Intérpretes \\
\hline \multirow[t]{12}{*}{ Jara, Víctor } & El cigarrito (1964). & $24 / 07 / 2011$ & $\begin{array}{l}\text { Plaza del Ayuntamiento } \\
\text { de Toledo, España }\end{array}$ & $\begin{array}{l}\text { Orquesta de Jazz UCV Big } \\
\text { Bang. }\end{array}$ \\
\hline & & $26 / 07 / 2011$ & $\begin{array}{l}\text { Ciclo de Conciertos } \\
\text { Veranos de la Villa de } \\
\text { Madrid, España. }\end{array}$ & $\begin{array}{l}\text { Orquesta de Jazz UCV Big- } \\
\text { Bang. }\end{array}$ \\
\hline & & $27 / 07 / 2011$ & $\begin{array}{l}\text { Penelles, Lleida, Plaza } \\
\text { Central, España. }\end{array}$ & $\begin{array}{l}\text { Orquesta de Jazz UCV Big- } \\
\text { Bang. }\end{array}$ \\
\hline & & $28 / 07 / 2011$ & $\begin{array}{l}\text { Teatro Liceu de } \\
\text { Barcelona, España. }\end{array}$ & $\begin{array}{l}\text { Orquesta de Jazz UCV Big- } \\
\text { Bang. }\end{array}$ \\
\hline & & $29 / 07 / 2011$ & $\begin{array}{l}\text { Festival Terrassa d’Stiu } \\
\text { Plaza, Lluis Companys de } \\
\text { Terrassa, España. }\end{array}$ & $\begin{array}{l}\text { Orquesta de Jazz UCV Big- } \\
\text { Bang. }\end{array}$ \\
\hline & & $30 / 07 / 2011$ & $\begin{array}{l}\text { Sede de los Castellers de } \\
\text { Vilafranca, España. }\end{array}$ & $\begin{array}{l}\text { Orquesta de Jazz UCV Big- } \\
\text { Bang. }\end{array}$ \\
\hline & $\begin{array}{l}\text { Te recuerdo, Amanda } \\
\text { (1968). }\end{array}$ & $24 / 07 / 2011$ & $\begin{array}{l}\text { Plaza del Ayuntamiento } \\
\text { de Toledo, España. }\end{array}$ & $\begin{array}{l}\text { Orquesta de Jazz UCV Big } \\
\text { Bang. }\end{array}$ \\
\hline & & $26 / 07 / 2011$ & $\begin{array}{l}\text { Ciclo de Conciertos } \\
\text { Veranos de la Villa de } \\
\text { Madrid, España. }\end{array}$ & $\begin{array}{l}\text { Orquesta de Jazz UCV Big- } \\
\text { Bang. }\end{array}$ \\
\hline & & $27 / 07 / 2011$ & $\begin{array}{l}\text { Penelles, Lleida, Plaza } \\
\text { Central, España. }\end{array}$ & $\begin{array}{l}\text { Orquesta de Jazz UCV Big- } \\
\text { Bang. }\end{array}$ \\
\hline & & $28 / 07 / 2011$ & $\begin{array}{l}\text { Teatro Liceu de } \\
\text { Barcelona, España }\end{array}$ & $\begin{array}{l}\text { Orquesta de Jazz UCV Big- } \\
\text { Bang. }\end{array}$ \\
\hline & & 29/07/2011 & $\begin{array}{l}\text { Festival Terrassa d’Stiu } \\
\text { Plaza Lluis Companys de } \\
\text { Terrassa, España. }\end{array}$ & $\begin{array}{l}\text { Orquesta de Jazz UCV Big- } \\
\text { Bang. }\end{array}$ \\
\hline & & $30 / 07 / 2011$ & $\begin{array}{l}\text { Sede de los Castellers de } \\
\text { Vilafranca, España. }\end{array}$ & $\begin{array}{l}\text { Orquesta de Jazz UCV Big- } \\
\text { Bang. }\end{array}$ \\
\hline Krause, Juan & $\begin{array}{l}\text { Los clarines de Maipú, } \\
\text { polka militar (1864). }\end{array}$ & 03/08/2011 & $\begin{array}{l}\text { Joyas musicales de salón, } \\
\text { Chile, 1850-1950, Sala } \\
\text { Isidora Zegers, Facultad } \\
\text { de Artes, Universidad de } \\
\text { Chile. }\end{array}$ & $\begin{array}{l}\text { Marcela Lillo, piano; Felipe } \\
\text { González, percusión. }\end{array}$ \\
\hline $\begin{array}{l}\text { La Rivera, } \\
\text { Eduviges de }\end{array}$ & $\begin{array}{l}\text { La Chimba de Copiapó } \\
\text { (1876). }\end{array}$ & 03/08/2011 & $\begin{array}{l}\text { Joyas musicales de salón, } \\
\text { Chile, 1850-1950, Sala } \\
\text { Isidora Zegers, Facultad } \\
\text { de Artes, Universidad de } \\
\text { Chile }\end{array}$ & Marcela Lillo, piano. \\
\hline Lefever, Tomás & $\begin{array}{l}\text { Sinfonía } 1964 \text { (1964) } \\
\text { para orquesta (dedicada a } \\
\text { León Schidlowsky). }\end{array}$ & $9,10 / 09 / 2011$ & $\begin{array}{l}\text { Teatro Universidad de } \\
\text { Chile. }\end{array}$ & $\begin{array}{l}\text { Orquesta Sinfónica de Chile, } \\
\text { Michal Nesterowicz, director. }\end{array}$ \\
\hline Leng, Alfonso & $\begin{array}{l}\text { Andante (1905-1912) para } \\
\text { cuerdas. }\end{array}$ & $17 / 04 / 2011$ & $\begin{array}{l}\text { Campus Bellavista, } \\
\text { Universidad San } \\
\text { Sebastián. }\end{array}$ & $\begin{array}{l}\text { Orquesta Universidad San } \\
\text { Sebastián, Denis Kolobov, } \\
\text { director. }\end{array}$ \\
\hline
\end{tabular}




\begin{tabular}{|c|c|c|c|c|}
\hline $\begin{array}{l}\text { Nombre del } \\
\text { Compositor }\end{array}$ & Título de la obra & $\begin{array}{l}\text { Fecha de } \\
\text { Interpretación }\end{array}$ & Lugar & Intérpretes \\
\hline \multirow[t]{3}{*}{ Leng, Alfonso } & & 23/03/2011 & Valdivia. & $\begin{array}{l}\text { Orquesta de Cámara de } \\
\text { Valdivia, Cristóbal Urrutia, } \\
\text { director. }\end{array}$ \\
\hline & $\begin{array}{l}\text { Cuatro doloras (1946) para } \\
\text { piano. }\end{array}$ & $25 / 05 / 2011$ & $\begin{array}{l}\text { "Ciclo música chilena y } \\
\text { latinoamericana": } \\
\text { "Del romanticismo } \\
\text { al neoclasicismo en } \\
\text { Latinoamérica", } \\
\text { Sala Isidora Zegers, } \\
\text { Facultad de Artes, } \\
\text { Universidad de Chile. }\end{array}$ & Jorge Pepi-Alos, piano. \\
\hline & & $28 / 06 / 2011$ & $\begin{array}{l}\text { Temporada Oficial de } \\
\text { Conciertos Universidad } \\
\text { de Chile, Centro Cultural } \\
\text { Gabriela Mistral (GAM). }\end{array}$ & Jorge Pepi-Alos, piano. \\
\hline $\begin{array}{l}\text { Letelier, } \\
\text { Alfonso }\end{array}$ & $\begin{array}{l}\text { Suite grotesca }(1936) \text { en } \\
\text { versión para fagot y piano. }\end{array}$ & $07 / 09 / 2011$ & $\begin{array}{l}\text { Ciclo de música chilena } \\
\text { y latinoamericana, Sala } \\
\text { Isidora Zegers, Facultad } \\
\text { de Artes de la Universidad } \\
\text { de Chile. }\end{array}$ & $\begin{array}{l}\text { Jorge Espinoza F., fagot; } \\
\text { Patricia Castro, piano. }\end{array}$ \\
\hline \multirow[t]{2}{*}{ Letelier, Miguel } & $\begin{array}{l}\text { Instantes (1966) para gran } \\
\text { orquesta. }\end{array}$ & $9,10 / 09 / 2011$ & $\begin{array}{l}\text { Teatro Universidad de } \\
\text { Chile. }\end{array}$ & $\begin{array}{l}\text { Orquesta Sinfónica de Chile, } \\
\text { Michal Nesterowicz, director. }\end{array}$ \\
\hline & $\begin{array}{l}\text { Divertimento (1964) para } \\
\text { flauta, oboe, clarinete, } \\
\text { cuarteto de cuerdas y } \\
\text { clave. }\end{array}$ & 19/06/2011 & $\begin{array}{l}\text { Festival Internacional "La } \\
\text { música en el Di Tella", } \\
\text { Centro Cultural Borges, } \\
\text { Argentina. }\end{array}$ & $\begin{array}{l}\text { Sergio Catalán, flauta; María } \\
\text { Eugenia Marsili, oboe; Javier } \\
\text { Mariani, clarinete; Elena } \\
\text { Buchbinder y Carlos Britez, } \\
\text { violines; Manuel de Olaso, } \\
\text { clave. }\end{array}$ \\
\hline Loyola, Margot & Cachimbos. & 03/08/2011 & $\begin{array}{l}\text { Joyas musicales de salón, } \\
\text { Chile, 1850-1950, Sala } \\
\text { Isidora Zegers, Facultad } \\
\text { de Artes, Universidad de } \\
\text { Chile. }\end{array}$ & $\begin{array}{l}\text { Marcela Lillo, piano; Felipe } \\
\text { González, percusión. }\end{array}$ \\
\hline $\begin{array}{l}\text { Manfredi, } \\
\text { Enrique }\end{array}$ & $\begin{array}{l}\text { Los clarinetes de Concón, } \\
\text { pasodoble (siglo XIX). }\end{array}$ & 03/08/2011 & $\begin{array}{l}\text { Joyas musicales de salón, } \\
\text { Chile, 1850-1950, Sala } \\
\text { Isidora Zegers, Facultad } \\
\text { de Artes, Universidad de } \\
\text { Chile. }\end{array}$ & $\begin{array}{l}\text { Marcela Lillo, piano; Felipe } \\
\text { González, percusión. }\end{array}$ \\
\hline \multirow[t]{3}{*}{$\begin{array}{l}\text { Matamoros, } \\
\text { Ximena }\end{array}$} & $E \cos (2006)$ para guitarra. & $26 / 08 / 2011$ & $\begin{array}{l}\text { Música latinoamericana, } \\
\text { Iglesia Santiago Centro. }\end{array}$ & Ximena Matamoros, guitarra. \\
\hline & & $31 / 08 / 2011$ & $\begin{array}{l}\text { Ciclo de música chilena } \\
\text { y latinoamericana, Sala } \\
\text { Isidora Zegers, Facultad } \\
\text { de Artes, Universidad de } \\
\text { Chile. }\end{array}$ & Ximena Matamoros, guitarra. \\
\hline & & $7 / 09 / 2011$ & $\begin{array}{l}\text { Música latinoamericana, } \\
\text { Registro Civil Santiago } \\
\text { Centro. }\end{array}$ & Ximena Matamoros, guitarra. \\
\hline
\end{tabular}




\begin{tabular}{|c|c|c|c|c|}
\hline $\begin{array}{l}\text { Nombre del } \\
\text { Compositor }\end{array}$ & Título de la obra & $\begin{array}{l}\text { Fecha de } \\
\text { Interpretación }\end{array}$ & Lugar & Intérpretes \\
\hline \multirow[t]{2}{*}{$\begin{array}{l}\text { Matamoros, } \\
\text { Ximena }\end{array}$} & $\begin{array}{l}\text { Océano (Blues) (2001) } \\
\text { para guitarra. }\end{array}$ & $31 / 08 / 2011$ & $\begin{array}{l}\text { Ciclo de música chilena } \\
\text { y latinoamericana, Sala } \\
\text { Isidora Zegers, Facultad } \\
\text { de Artes, Universidad de } \\
\text { Chile. }\end{array}$ & Ximena Matamoros, guitarra. \\
\hline & $\begin{array}{l}\text { Reminiscencias (Swing } \\
\text { Feel) (2003) para } \\
\text { guitarra. }\end{array}$ & $31 / 08 / 2011$ & $\begin{array}{l}\text { Ciclo de música chilena } \\
\text { y latinoamericana, Sala } \\
\text { Isidora Zegers, Facultad } \\
\text { de Artes, Universidad de } \\
\text { Chile. }\end{array}$ & Ximena Matamoros, guitarra. \\
\hline \multirow[t]{2}{*}{$\begin{array}{l}\text { Matthey, } \\
\text { Gabriel }\end{array}$} & $\begin{array}{l}\text { Cuarteto primero (2009) } \\
\text { para guitarras. }\end{array}$ & $\begin{array}{l}14 / 05 / 2011 \\
\text { (estreno) }\end{array}$ & $\begin{array}{l}\text { Festival de Guitarra de } \\
\text { Lausanne, Suiza. }\end{array}$ & $\begin{array}{l}\text { Cuarteto de Guitarras de } \\
\text { Chile. }\end{array}$ \\
\hline & $\begin{array}{l}\text { Concierto primero (2004) } \\
\text { para guitarra y orquesta, } \\
\text { de la serie "Conciertos de } \\
\text { Última Generación". }\end{array}$ & $\begin{array}{l}9 / 07 / 2011 \\
\text { (reestreno) }\end{array}$ & $\begin{array}{l}\text { Teatro Universidad de } \\
\text { Concepción. }\end{array}$ & $\begin{array}{l}\text { Orquesta Sinfónica } \\
\text { de Concepción, Brian } \\
\text { Cole, director; Mauricio } \\
\text { Valdebenito, guitarra. }\end{array}$ \\
\hline \multirow[t]{3}{*}{$\begin{array}{l}\text { Maupoint, } \\
\text { Andrés }\end{array}$} & $\begin{array}{l}\text { Árbol sin hojas (1989) } \\
\text { de Cinco imágenes para } \\
\text { orquesta. }\end{array}$ & $11 / 05 / 2011$ & $\begin{array}{l}\text { Corporación Cultural de } \\
\text { las Condes. }\end{array}$ & $\begin{array}{l}\text { Orquesta de Cámara de Chile, } \\
\text { Rodolfo Fischer, director. }\end{array}$ \\
\hline & & $13 / 05 / 2011$ & $\begin{array}{l}\text { Teatro Municipal de } \\
\text { Ñuñoa. }\end{array}$ & $\begin{array}{l}\text { Orquesta de Cámara de Chile, } \\
\text { Rodolfo Fischer, director. }\end{array}$ \\
\hline & & $14 / 05 / 2011$ & Catedral de Rancagua. & $\begin{array}{l}\text { Orquesta de Cámara de Chile, } \\
\text { Rodolfo Fischer, director. }\end{array}$ \\
\hline \multirow[t]{2}{*}{$\begin{array}{l}\text { Molinare, } \\
\text { Nicanor }\end{array}$} & $\begin{array}{l}\text { Cocorocó, corrido (siglo } \\
\mathrm{XX} \text { ). }\end{array}$ & 03/08/2011 & $\begin{array}{l}\text { Joyas musicales de salón, } \\
\text { Chile, 1850-1950, Sala } \\
\text { Isidora Zegers, Facultad } \\
\text { de Artes, Universidad de } \\
\text { Chile. }\end{array}$ & $\begin{array}{l}\text { Marcela Lillo, piano; Felipe } \\
\text { González, percusión. }\end{array}$ \\
\hline & $\begin{array}{l}\text { Chiu-chiu, corrido one- } \\
\text { step (siglo XX). }\end{array}$ & 03/08/2011 & $\begin{array}{l}\text { Joyas musicales de salón, } \\
\text { Chile, 1850-1950, Sala } \\
\text { Isidora Zegers, Facultad } \\
\text { de Artes, Universidad de } \\
\text { Chile. }\end{array}$ & $\begin{array}{l}\text { Marcela Lillo, piano; Felipe } \\
\text { González, percusión. }\end{array}$ \\
\hline Mora, Mario & $\begin{array}{l}\text { Nada (2010) para } \\
\text { contrabajo y electrónica. }\end{array}$ & $31 / 05 / 2011$ & $\begin{array}{l}\text { Ciclo de música del } \\
\text { siglo XX y XXI, Centro } \\
\text { Cultural Gabriela Mistral } \\
\text { (GAM). }\end{array}$ & $\begin{array}{l}\text { Concierto "Gráficas digitales, } \\
\text { danza y electrónica en } \\
\text { tiempo real", Carlos Arenas, } \\
\text { contrabajo. }\end{array}$ \\
\hline $\begin{array}{l}\text { Morales, } \\
\text { Cristián }\end{array}$ & $\begin{array}{l}\text { Relief VI (2011) para } \\
\text { guitarra y dispositivo } \\
\text { electroacústico. }\end{array}$ & $19 / 05 / 2011$ & $\begin{array}{l}\text { Centro Cultural Gabriela } \\
\text { Mistral (GAM). }\end{array}$ & Diego Castro, guitarra. \\
\hline Ohlsen, Oscar & $\begin{array}{l}\text { Suite sobre aires chilenos } \\
\text { (2007) para dúo de } \\
\text { guitarras: } \\
\text { - Impresiones sobre una } \\
\text { canción de Luis Advis. } \\
\text { - Vamos a Belén, pastores } \\
\text { (Villancico de Chiloé). } \\
\text { - La Malaheña (Canción de } \\
\text { Chiloé). } \\
\text { - Palomita. }\end{array}$ & $22 / 06 / 2011$ & $\begin{array}{l}\text { Ciclo de música chilena } \\
\text { y latinoamericana, Sala } \\
\text { Isidora Zegers, Facultad } \\
\text { de Artes, Universidad de } \\
\text { Chile. }\end{array}$ & Dúo Orellana \& Orlandini. \\
\hline
\end{tabular}




\begin{tabular}{|c|c|c|c|c|}
\hline $\begin{array}{l}\text { Nombre del } \\
\text { Compositor }\end{array}$ & Título de la obra & $\begin{array}{l}\text { Fecha de } \\
\text { Interpretación }\end{array}$ & Lugar & Intérpretes \\
\hline \multirow[t]{2}{*}{$\begin{array}{l}\text { Orrego-Salas, } \\
\text { Juan }\end{array}$} & $\begin{array}{l}\text { Concierto }(1980) \text { para } \\
\text { oboe y orquesta. }\end{array}$ & $30 / 04 / 2011$ & $\begin{array}{l}\text { Teatro Municipal de } \\
\text { Ñuñoa. }\end{array}$ & $\begin{array}{l}\text { Jorge Galán, oboe; } \\
\text { Orquesta de Cámara de Chile, } \\
\text { Mario Videla, director. }\end{array}$ \\
\hline & Rústica (1952) para piano. & $05 / 08 / 2011$ & $\begin{array}{l}\text { Sala América, Biblioteca } \\
\text { Nacional. }\end{array}$ & Daniel Saavedra, piano. \\
\hline Osorio, Daniel & $\begin{array}{l}Y \text { después, silencio... (2011) } \\
\text { para orquesta y soprano } \\
\text { recitante. }\end{array}$ & $22,23 / 07 / 2011$ & $\begin{array}{l}\text { Centro de Extensión } \\
\text { Artística y Cultural } \\
\text { Domingo Santa Cruz, } \\
\text { Teatro Universidad de } \\
\text { Chile. }\end{array}$ & $\begin{array}{l}\text { Orquesta Sinfónica de Chile, } \\
\text { Charles Olivieri-Munroe, } \\
\text { director invitado; Nancy } \\
\text { Gómez, soprano recitante. }\end{array}$ \\
\hline \multirow[t]{8}{*}{ Parra, Violeta } & $\begin{array}{l}\text { Anticueca } \mathrm{N}^{\circ} 4 \text { (1957) } \\
\text { Cueca valseada (guitarra } \\
\text { transpuesta), } \\
\text { Casamiento de negros } \\
\text { (1953), } \\
\text { El amor }(2006), \\
\text { La jardinera }(1953) .\end{array}$ & $11 / 05 / 2011$ & $\begin{array}{l}\text { Sala de Conciertos, } \\
\text { Universidad de Tula, Tula, } \\
\text { Rusia. }\end{array}$ & $\begin{array}{l}\text { Dúo Álvarez-Henríquez: } \\
\text { Ana Álvarez Kemp, soprano; } \\
\text { Patricio Henríquez Ulloa, } \\
\text { guitarra clásica. }\end{array}$ \\
\hline & & $13 / 05 / 2011$ & $\begin{array}{l}\text { IX Festival de Música } \\
\text { Universo del Sonido, } \\
\text { Cantos de Chile, un relato } \\
\text { bicentenario en Europa, } \\
\text { Sala Rachmaninov } \\
\text { del Conservatorio } \\
\text { Tchaikovsky, Moscú. }\end{array}$ & Dúo Álvarez-Henríquez. \\
\hline & & $14 / 05 / 2011$ & $\begin{array}{l}\text { Sala de Conciertos, } \\
\text { Universidad de Saoksky, } \\
\text { Saoksky, Rusia. }\end{array}$ & Dúo Álvarez-Henríquez. \\
\hline & & $15 / 05 / 2011$ & $\begin{array}{l}\text { Sala de Publicaciones, } \\
\text { Universidad de Saoksky, } \\
\text { Saoksky, Rusia. }\end{array}$ & Dúo Álvarez-Henríquez. \\
\hline & & $17 / 05 / 2011$ & $\begin{array}{l}\text { Salón Filarmónico, Teatro } \\
\text { Municipal de Tula, Tula, } \\
\text { Rusia. }\end{array}$ & Dúo Álvarez-Henríquez. \\
\hline & & $24 / 05 / 2011$ & $\begin{array}{l}\text { Sala de Sesiones, División } \\
\text { Euroasiática Organización } \\
\text { Iglesia Adventista del } \\
\text { 7mo. Día Chilena, Moscú. }\end{array}$ & Dúo Álvarez-Henríquez. \\
\hline & & $28 / 05 / 2011$ & $\begin{array}{l}\text { Teatro Moulin D'Ande, } \\
\text { Centro Cultural Moulin } \\
\text { D'Ande, Normandie, } \\
\text { Francia. }\end{array}$ & Dúo Álvarez-Henríquez. \\
\hline & & $13 / 05 / 2011$ & $\begin{array}{l}\text { IX Festival de Música } \\
\text { Universo del Sonido, } \\
\text { Cantos de Chile, un relato } \\
\text { bicentenario en Europa, } \\
\text { Sala Rachmaninov } \\
\text { del Conservatorio } \\
\text { Tchaikovsky, Moscú. }\end{array}$ & Dúo Álvarez-Henríquez. \\
\hline
\end{tabular}




\begin{tabular}{|c|c|c|c|c|}
\hline $\begin{array}{l}\text { Nombre del } \\
\text { Compositor }\end{array}$ & Título de la obra & $\begin{array}{l}\text { Fecha de } \\
\text { Interpretación }\end{array}$ & Lugar & Intérpretes \\
\hline \multirow[t]{13}{*}{ Parra, Violeta } & & $14 / 05 / 2011$ & $\begin{array}{l}\text { Sala de Conciertos, } \\
\text { Universidad de Saoksky, } \\
\text { Saoksky, Rusia. }\end{array}$ & $\begin{array}{l}\text { Dúo Álvarez-Henríquez: } \\
\text { Ana Álvarez Kemp, soprano, } \\
\text { Patricio Henríquez Ulloa, } \\
\text { guitarra clásica. }\end{array}$ \\
\hline & & $15 / 05 / 2011$ & $\begin{array}{l}\text { Sala de Publicaciones, } \\
\text { Universidad de Saoksky, } \\
\text { Saoksky, Rusia. }\end{array}$ & Dúo Álvarez-Henríquez. \\
\hline & & $17 / 05 / 2011$ & $\begin{array}{l}\text { Salón Filarmónico, Teatro } \\
\text { Municipal de Tula, Tula, } \\
\text { Rusia. }\end{array}$ & Dúo Álvarez-Henríquez. \\
\hline & & $24 / 05 / 2011$ & $\begin{array}{l}\text { Sala de Sesiones, División } \\
\text { Euroasiática Organización } \\
\text { Iglesia Adventista del } \\
\text { 7mo. Día Chilena, Moscú. }\end{array}$ & Dúo Álvarez-Henríquez. \\
\hline & & $28 / 05 / 2011$ & $\begin{array}{l}\text { Teatro Moulin D'Ande, } \\
\text { Centro Cultural Moulin } \\
\text { D'Ande, Normandie, } \\
\text { Francia. }\end{array}$ & Dúo Álvarez-Henríquez. \\
\hline & \multirow[t]{8}{*}{ Gracias a la vida (1966). } & $11 / 05 / 2011$ & $\begin{array}{l}\text { Sala de Conciertos, } \\
\text { Universidad de Tula, Tula, } \\
\text { Rusia. }\end{array}$ & Dúo Álvarez-Henríquez. \\
\hline & & $13 / 05 / 2011$ & $\begin{array}{l}\text { IX Festival de Música } \\
\text { Universo del Sonido, } \\
\text { Cantos de Chile, un relato } \\
\text { bicentenario en Europa, } \\
\text { Sala Rachmaninov } \\
\text { del Conservatorio } \\
\text { Tchaikovsky, Moscú. }\end{array}$ & Dúo Álvarez-Henríquez. \\
\hline & & $14 / 05 / 2011$ & $\begin{array}{l}\text { Sala de Conciertos, } \\
\text { Universidad de Saoksky, } \\
\text { Saoksky, Rusia. }\end{array}$ & Dúo Álvarez-Henríquez. \\
\hline & & $15 / 05 / 2011$ & $\begin{array}{l}\text { Sala de Publicaciones, } \\
\text { Universidad de Saoksky, } \\
\text { Saoksky, Rusia. }\end{array}$ & Dúo Álvarez-Henríquez. \\
\hline & & $17 / 05 / 2011$ & $\begin{array}{l}\text { Salón Filarmónico, Teatro } \\
\text { Municipal de Tula, Tula, } \\
\text { Rusia. }\end{array}$ & Dúo Álvarez-Henríquez. \\
\hline & & $24 / 05 / 2011$ & $\begin{array}{l}\text { Sala de Sesiones, División } \\
\text { Euroasiática Organización } \\
\text { Iglesia Adventista del } \\
\text { 7mo. Día Chilena, Moscú. }\end{array}$ & Dúo Álvarez-Henríquez. \\
\hline & & $28 / 05 / 2011$ & $\begin{array}{l}\text { Teatro Moulin D'Ande, } \\
\text { Centro Cultural Moulin } \\
\text { D'Ande, Normandie, } \\
\text { Francia. }\end{array}$ & Dúo Álvarez-Henríquez. \\
\hline & & $24 / 07 / 2011$ & $\begin{array}{l}\text { Plaza del Ayuntamiento } \\
\text { de Toledo, España. }\end{array}$ & $\begin{array}{l}\text { Orquesta de Jazz UCV Big } \\
\text { Bang. }\end{array}$ \\
\hline
\end{tabular}




\begin{tabular}{|c|c|c|c|c|}
\hline $\begin{array}{l}\text { Nombre del } \\
\text { Compositor }\end{array}$ & Título de la obra & $\begin{array}{l}\text { Fecha de } \\
\text { Interpretación }\end{array}$ & Lugar & Intérpretes \\
\hline \multirow[t]{17}{*}{ Parra, Violeta } & & $26 / 07 / 2011$ & $\begin{array}{l}\text { Ciclo de Conciertos } \\
\text { Veranos de la Villa de } \\
\text { Madrid, España. }\end{array}$ & $\begin{array}{l}\text { Orquesta de Jazz UCV Big- } \\
\text { Bang. }\end{array}$ \\
\hline & & $27 / 07 / 2011$ & $\begin{array}{l}\text { Penelles, Lleida, Plaza } \\
\text { Central, España. }\end{array}$ & $\begin{array}{l}\text { Orquesta de Jazz UCV Big- } \\
\text { Bang. }\end{array}$ \\
\hline & & $28 / 07 / 2011$ & $\begin{array}{l}\text { Teatro Liceu de } \\
\text { Barcelona, España }\end{array}$ & $\begin{array}{l}\text { Orquesta de Jazz UCV Big- } \\
\text { Bang. }\end{array}$ \\
\hline & & $29 / 07 / 2011$ & $\begin{array}{l}\text { Festival Terrassa d'Stiu, } \\
\text { Plaza Lluis Companys de } \\
\text { Terrassa, España. }\end{array}$ & $\begin{array}{l}\text { Orquesta de Jazz UCV Big- } \\
\text { Bang. }\end{array}$ \\
\hline & & $30 / 07 / 2011$ & $\begin{array}{l}\text { Sede de los Castellers de } \\
\text { Vilafranca, España. }\end{array}$ & $\begin{array}{l}\text { Orquesta de Jazz UCV Big- } \\
\text { Bang. }\end{array}$ \\
\hline & $\begin{array}{l}\text { Run Run se fue pa'l Norte } \\
\text { (1966). }\end{array}$ & $24 / 07 / 2011$ & $\begin{array}{l}\text { Plaza del Ayuntamiento } \\
\text { de Toledo, España. }\end{array}$ & $\begin{array}{l}\text { Orquesta de Jazz UCV Big- } \\
\text { Bang. }\end{array}$ \\
\hline & & $26 / 07 / 2011$ & $\begin{array}{l}\text { Ciclo de Conciertos } \\
\text { Veranos de la Villa de } \\
\text { Madrid, España }\end{array}$ & $\begin{array}{l}\text { Orquesta de Jazz UCV Big- } \\
\text { Bang. }\end{array}$ \\
\hline & & $27 / 07 / 2011$ & $\begin{array}{l}\text { Penelles, Lleida, Plaza } \\
\text { Central, España. }\end{array}$ & $\begin{array}{l}\text { Orquesta de Jazz UCV Big- } \\
\text { Bang. }\end{array}$ \\
\hline & & $28 / 07 / 2011$ & $\begin{array}{l}\text { Teatro Liceu de } \\
\text { Barcelona, España. }\end{array}$ & $\begin{array}{l}\text { Orquesta de Jazz UCV Big- } \\
\text { Bang. }\end{array}$ \\
\hline & & $29 / 07 / 2011$ & $\begin{array}{l}\text { Festival Terrassa d'Stiu } \\
\text { Plaza Lluis Companys de } \\
\text { Terrassa, España. }\end{array}$ & $\begin{array}{l}\text { Orquesta de Jazz UCV Big- } \\
\text { Bang. }\end{array}$ \\
\hline & & $30 / 07 / 2011$ & $\begin{array}{l}\text { Sede de los Castellers de } \\
\text { Vilafranca, España. }\end{array}$ & $\begin{array}{l}\text { Orquesta de Jazz UCV Big- } \\
\text { Bang. }\end{array}$ \\
\hline & Volver a los diecisiete (1966). & $24 / 07 / 2011$ & $\begin{array}{l}\text { Plaza del Ayuntamiento } \\
\text { de Toledo, España. }\end{array}$ & $\begin{array}{l}\text { Orquesta de Jazz UCV Big } \\
\text { Bang. }\end{array}$ \\
\hline & & $26 / 07 / 2011$ & $\begin{array}{l}\text { Ciclo de Conciertos } \\
\text { Veranos de la Villa de } \\
\text { Madrid, España. }\end{array}$ & $\begin{array}{l}\text { Orquesta de Jazz UCV Big- } \\
\text { Bang. }\end{array}$ \\
\hline & & $27 / 07 / 2011$ & $\begin{array}{l}\text { Penelles, Lleida, Plaza } \\
\text { Central, España. }\end{array}$ & $\begin{array}{l}\text { Orquesta de Jazz UCV Big- } \\
\text { Bang. }\end{array}$ \\
\hline & & $28 / 07 / 2011$ & $\begin{array}{l}\text { Teatro Liceu de } \\
\text { Barcelona, España. }\end{array}$ & $\begin{array}{l}\text { Orquesta de Jazz UCV Big- } \\
\text { Bang. }\end{array}$ \\
\hline & & $29 / 07 / 2011$ & $\begin{array}{l}\text { Festival Terrassa d'Stiu } \\
\text { Plaza Lluis Companys de } \\
\text { Terrassa, España. }\end{array}$ & $\begin{array}{l}\text { Orquesta de Jazz UCV Big- } \\
\text { Bang. }\end{array}$ \\
\hline & & $30 / 07 / 2011$ & $\begin{array}{l}\text { Sede de los Castellers de } \\
\text { Vilafranca, España. }\end{array}$ & $\begin{array}{l}\text { Orquesta de Jazz UCV Big- } \\
\text { Bang. }\end{array}$ \\
\hline
\end{tabular}




\begin{tabular}{|c|c|c|c|c|}
\hline $\begin{array}{l}\text { Nombre del } \\
\text { Compositor }\end{array}$ & Título de la obra & $\begin{array}{l}\text { Fecha de } \\
\text { Interpretación }\end{array}$ & Lugar & Intérpretes \\
\hline R. de S. , Celia & $\begin{array}{l}\text { La instrucción de la mujer, } \\
\text { polka (1877). }\end{array}$ & 03/08/2011 & $\begin{array}{l}\text { Joyas musicales de salón, } \\
\text { Chile, 1850-1950, Sala } \\
\text { Isidora Zegers, Facultad } \\
\text { de Artes, Universidad de } \\
\text { Chile. }\end{array}$ & Marcela Lillo, piano. \\
\hline $\begin{array}{l}\text { Ramírez, } \\
\text { Hernán }\end{array}$ & $\begin{array}{l}\text { ** Música }(2010) \text { para } \\
\text { orquesta y guitarra quasi } \\
\text { solista obligata. }\end{array}$ & 08/07/2011 & $\begin{array}{l}\text { Teatro Municipal de La } \\
\text { Serena. }\end{array}$ & $\begin{array}{l}\text { Luis Orlandini, guitarra; } \\
\text { Orquesta Sinfónica de La } \\
\text { Serena, Pablo Carrasco, } \\
\text { director. }\end{array}$ \\
\hline $\begin{array}{l}\text { Rehbein, } \\
\text { Sebastián }\end{array}$ & $\begin{array}{l}\text { Tempranera (1999) para } \\
\text { conjunto de cámara. }\end{array}$ & 04/09/2011 & $\begin{array}{l}\text { Auditorio Universidad de } \\
\text { los Andes, San Carlos de } \\
\text { Apoquindo, Santiago. }\end{array}$ & $\begin{array}{l}\text { Camerata Universidad de } \\
\text { los Andes, Eduardo Browne, } \\
\text { director. }\end{array}$ \\
\hline \multirow[t]{7}{*}{$\begin{array}{l}\text { Reyes, Ana } \\
\text { María }\end{array}$} & Tonada. & $11 / 05 / 2011$ & $\begin{array}{l}\text { Sala de Conciertos, } \\
\text { Universidad de Tula, Tula, } \\
\text { Rusia. }\end{array}$ & $\begin{array}{l}\text { Dúo Álvarez-Henríquez: } \\
\text { Ana Álvarez Kemp, soprano; } \\
\text { Patricio Henríquez Ulloa, } \\
\text { guitarra clásica. }\end{array}$ \\
\hline & & $13 / 05 / 2011$ & $\begin{array}{l}\text { IX Festival de Música } \\
\text { Universo del Sonido, } \\
\text { Cantos de Chile, un relato } \\
\text { bicentenario en Europa, } \\
\text { Sala Rachmaninov } \\
\text { del Conservatorio } \\
\text { Tchaikovsky, Moscú. }\end{array}$ & Dúo Álvarez-Henríquez. \\
\hline & & $14 / 05 / 2011$ & $\begin{array}{l}\text { Sala de Conciertos, } \\
\text { Universidad de Saoksky, } \\
\text { Saoksky, Rusia. }\end{array}$ & Dúo Álvarez-Henríquez. \\
\hline & & $15 / 05 / 2011$ & $\begin{array}{l}\text { Sala de Publicaciones, } \\
\text { Universidad de Saoksky, } \\
\text { Saoksky, Rusia. }\end{array}$ & Dúo Álvarez-Henríquez. \\
\hline & & $17 / 05 / 2011$ & $\begin{array}{l}\text { Salón Filarmónico, Teatro } \\
\text { Municipal de Tula, Tula, } \\
\text { Rusia. }\end{array}$ & Dúo Álvarez-Henríquez. \\
\hline & & $24 / 05 / 2011$ & $\begin{array}{l}\text { Sala de Sesiones, División } \\
\text { Euroasiática Organización } \\
\text { Iglesia Adventista del } \\
\text { 7mo. Día Chilena, Moscú. }\end{array}$ & Dúo Álvarez-Henríquez. \\
\hline & & $28 / 05 / 2011$ & $\begin{array}{l}\text { Teatro Moulin D'Ande, } \\
\text { Centro Cultural Moulin } \\
\text { D'Ande, Normandie, } \\
\text { Francia. }\end{array}$ & Dúo Álvarez-Henríquez. \\
\hline $\begin{array}{l}\text { Rodríguez, } \\
\text { Felipe }\end{array}$ & $\begin{array}{l}\text { Nimbo oscuro (2011) para } \\
\text { viola da gamba, voz y } \\
\text { electrónica. }\end{array}$ & $31 / 05 / 2011$ & $\begin{array}{l}\text { Concierto "Gráficas } \\
\text { digitales, danza y } \\
\text { electrónica en tiempo } \\
\text { real", Ciclo de música del } \\
\text { siglo XX y XXI, Centro } \\
\text { Cultural Gabriela Mistral } \\
\text { (GAM). }\end{array}$ & $\begin{array}{l}\text { Felipe Rodríguez, voz, Gina } \\
\text { Allende, viola da gamba. }\end{array}$ \\
\hline
\end{tabular}




\begin{tabular}{|c|c|c|c|c|}
\hline $\begin{array}{l}\text { Nombre del } \\
\text { Compositor }\end{array}$ & Título de la obra & $\begin{array}{l}\text { Fecha de } \\
\text { Interpretación }\end{array}$ & Lugar & Intérpretes \\
\hline $\begin{array}{l}\text { Rojas, } \\
\text { Guillermo }\end{array}$ & $\begin{array}{l}\text { Divertimento (1987) para } \\
\text { fagot y piano. }\end{array}$ & 07/09/2011 & $\begin{array}{l}\text { Ciclo de música chilena } \\
\text { y latinoamericana, Sala } \\
\text { Isidora Zegers, Facultad } \\
\text { de Artes de la Universidad } \\
\text { de Chile. }\end{array}$ & $\begin{array}{l}\text { Jorge Espinoza F., fagot; } \\
\text { Patricia Castro, piano. }\end{array}$ \\
\hline \multirow[t]{4}{*}{ Salinas, Horacio } & $\begin{array}{l}\text { Sensemayáa (texto de } \\
\text { Nicolás Guillén) (1978). }\end{array}$ & $\begin{array}{l}30 / 09 / 2011 \text { y } \\
1 / 10 / 2011\end{array}$ & $\begin{array}{l}\text { Teatro Universidad de } \\
\text { Concepción. }\end{array}$ & $\begin{array}{l}\text { Orquesta Sinfónica de la } \\
\text { Universidad de Concepción, } \\
\text { Rodrigo Tapia, director; Coro } \\
\text { Universidad de Concepción, } \\
\text { Carlos Traverso, director. }\end{array}$ \\
\hline & $\begin{array}{l}\text { El Mercado Testaccio } \\
(1981) .\end{array}$ & $\begin{array}{l}30 / 09 / 2011 \text { y } \\
1 / 10 / 2011\end{array}$ & $\begin{array}{l}\text { Teatro Universidad de } \\
\text { Concepción. }\end{array}$ & $\begin{array}{l}\text { Orquesta Sinfónica de la } \\
\text { Universidad de Concepción, } \\
\text { Rodrigo Tapia, director. }\end{array}$ \\
\hline & $\begin{array}{l}\text { Medianoche (texto de } \\
\text { Patricio Manns) (1992). }\end{array}$ & $\begin{array}{l}30 / 09 / 2011 y \\
1 / 10 / 2011\end{array}$ & $\begin{array}{l}\text { Teatro Universidad de } \\
\text { Concepción. }\end{array}$ & $\begin{array}{l}\text { Orquesta Sinfónica de la } \\
\text { Universidad de Concepción, } \\
\text { Rodrigo Tapia, director; Coro } \\
\text { Universidad de Concepción, } \\
\text { Carlos Traverso, director. }\end{array}$ \\
\hline & $\begin{array}{l}\text { La Rosa de los Vientos } \\
\text { (texto de Patricio Manns), } \\
\text { (1999). }\end{array}$ & $\begin{array}{l}30 / 09 / 2011 y \\
1 / 10 / 2011\end{array}$ & $\begin{array}{l}\text { Teatro Universidad de } \\
\text { Concepción. }\end{array}$ & $\begin{array}{l}\text { Orquesta Sinfónica de la } \\
\text { Universidad de Concepción, } \\
\text { Rodrigo Tapia, director; Coro } \\
\text { Universidad de Concepción, } \\
\text { Carlos Traverso, director. }\end{array}$ \\
\hline
\end{tabular}

\begin{tabular}{|c|c|c|c|c|}
\hline Salinas, Saúl & $\begin{array}{l}\text { Corazones partidos, cueca } \\
\text { (siglo XX). }\end{array}$ & 03/08/2011 & $\begin{array}{l}\text { Joyas musicales de salón, } \\
\text { Chile, 1850-1950, Sala } \\
\text { Isidora Zegers, Facultad } \\
\text { de Artes, Universidad de } \\
\text { Chile }\end{array}$ & Marcela Lillo, piano. \\
\hline \multirow[t]{5}{*}{$\begin{array}{l}\text { Sánchez, Juan } \\
\text { Antonio }\end{array}$} & \multirow[t]{5}{*}{$\begin{array}{l}\text { Tonada por despedida } \\
\text { (2002) para guitarra. }\end{array}$} & $23 / 05 / 2011$ & $\begin{array}{l}\text { Sala Isidora Zegers, } \\
\text { Facultad de Artes, } \\
\text { Universidad de Chile. }\end{array}$ & Karla García, guitarra. \\
\hline & & $11 / 05 / 2011$ & $\begin{array}{l}\text { Sala de Conciertos, } \\
\text { Universidad de Tula, Tula, } \\
\text { Rusia. }\end{array}$ & $\begin{array}{l}\text { Dúo Álvarez-Henríquez: } \\
\text { Ana Álvarez Kemp, soprano; } \\
\text { Patricio Henríquez Ulloa, } \\
\text { guitarra clásica. }\end{array}$ \\
\hline & & $13 / 05 / 2011$ & $\begin{array}{l}\text { IX Festival de Música } \\
\text { Universo del Sonido. } \\
\text { Cantos de Chile, un relato } \\
\text { bicentenario en Europa, } \\
\text { Sala Rachmaninov } \\
\text { del Conservatorio } \\
\text { Tchaikovsky, Moscú. }\end{array}$ & Dúo Álvarez-Henríquez. \\
\hline & & $14 / 05 / 2011$ & $\begin{array}{l}\text { Sala de Conciertos, } \\
\text { Universidad de Saoksky, } \\
\text { Saoksky, Rusia. }\end{array}$ & Dúo Álvarez-Henríquez. \\
\hline & & $15 / 05 / 2011$ & $\begin{array}{l}\text { Sala de Publicaciones, } \\
\text { Universidad de Saoksky, } \\
\text { Saoksky, Rusia. }\end{array}$ & Dúo Álvarez-Henríquez. \\
\hline
\end{tabular}




\begin{tabular}{|c|c|c|c|c|}
\hline $\begin{array}{l}\text { Nombre del } \\
\text { Compositor }\end{array}$ & Título de la obra & $\begin{array}{l}\text { Fecha de } \\
\text { Interpretación }\end{array}$ & Lugar & Intérpretes \\
\hline \multirow[t]{6}{*}{$\begin{array}{l}\text { Sánchez, Juan } \\
\text { Antonio }\end{array}$} & & $17 / 05 / 2011$ & $\begin{array}{l}\text { Salón Filarmónico, Teatro } \\
\text { Municipal de Tula, Tula, } \\
\text { Rusia. }\end{array}$ & $\begin{array}{l}\text { Dúo Álvarez-Henríquez: } \\
\text { Ana Álvarez Kemp, soprano; } \\
\text { Patricio Henríquez Ulloa, } \\
\text { guitarra clásica. }\end{array}$ \\
\hline & & $24 / 05 / 2011$ & $\begin{array}{l}\text { Sala de Sesiones, División } \\
\text { Euroasiática Organización } \\
\text { Iglesia Adventista del } \\
\text { 7mo. Día Chilena, Moscú. }\end{array}$ & Dúo Álvarez-Henríquez. \\
\hline & & $28 / 05 / 2011$ & $\begin{array}{l}\text { Teatro Moulin D'Ande, } \\
\text { Centro Cultural Moulin } \\
\text { D'Ande, Normandie, } \\
\text { Francia. }\end{array}$ & Dúo Álvarez-Henríquez. \\
\hline & $\begin{array}{l}\text { * Barcos en la oscuridad } \\
(2011) \text { para cuarteto de } \\
\text { guitarras. }\end{array}$ & $26 / 05 / 2011$ & $\begin{array}{l}\text { Centro Cultural Gabriela } \\
\text { Mistral (GAM). }\end{array}$ & $\begin{array}{l}\text { Cuarteto de guitarras: Oscar } \\
\text { Ohlsen, Luis Castro, Jorge } \\
\text { Valdivia y Hernán Rojas. }\end{array}$ \\
\hline & $\begin{array}{l}\text { Rin del adiós y Sirilla del } \\
\text { nuevo día }(2010) \text { para dúo } \\
\text { de guitarras. }\end{array}$ & 22/06/2011 & $\begin{array}{l}\text { Ciclo de música chilena } \\
\text { y latinoamericana, Sala } \\
\text { Isidora Zegers, Facultad } \\
\text { de Artes de la Universidad } \\
\text { de Chile. }\end{array}$ & Dúo Orellana \& Orlandini. \\
\hline & $\begin{array}{l}\text { Cuatro caminos (Norte, Sur, } \\
\text { Este, Oeste) (2007) para } \\
\text { dúo de guitarras. }\end{array}$ & 22/06/2011 & $\begin{array}{l}\text { Ciclo de música chilena } \\
\text { y latinoamericana, Sala } \\
\text { Isidora Zegers, Facultad } \\
\text { de Artes de la Universidad } \\
\text { de Chile. }\end{array}$ & Dúo Orellana \& Orlandini. \\
\hline $\begin{array}{l}\text { Santa Cruz, } \\
\text { Domingo }\end{array}$ & $\begin{array}{l}\text { Poema trágico } \mathrm{N}^{\circ} 5 \text {, op. } 11 \\
\text { (1929) para piano. }\end{array}$ & $22 / 08 / 2011$ & $\begin{array}{l}\text { Sala América, Biblioteca } \\
\text { Nacional. }\end{array}$ & Daniel Bahamondes, piano. \\
\hline $\begin{array}{l}\text { Schidlowsky, } \\
\text { León }\end{array}$ & $\begin{array}{l}\text { Vox clamantis in deserto } \\
(2000) \text { para orquesta. }\end{array}$ & $13,14 / 05 / 2011$ & $\begin{array}{l}\text { Teatro Universidad de } \\
\text { Chile. }\end{array}$ & $\begin{array}{l}\text { Orquesta Sinfónica de Chile, } \\
\text { Juan Pablo Izquierdo, director } \\
\text { invitado. }\end{array}$ \\
\hline \multirow[t]{2}{*}{ Soro, Enrique } & $\begin{array}{l}\text { Zamacueca }(1923) \text { para } \\
\text { piano. }\end{array}$ & $29 / 08 / 2011$ & $\begin{array}{l}\text { Sala América, Biblioteca } \\
\text { Nacional. }\end{array}$ & Javier Valenzuela, piano. \\
\hline & $\begin{array}{l}\text { Andante appassionato } \\
\text { (1916) para piano. }\end{array}$ & $12 / 09 / 2011$ & $\begin{array}{l}\text { Sala América, Biblioteca } \\
\text { Nacional. }\end{array}$ & Javier Moraga, piano. \\
\hline Stuardo, Marcos & Et (2010) para orquesta. & $12,13 / 08 / 2011$ & $\begin{array}{l}\text { Teatro Universidad de } \\
\text { Chile. }\end{array}$ & $\begin{array}{l}\text { Orquesta Sinfónica de Chile, } \\
\text { Andrew Gourlay, director } \\
\text { invitado. }\end{array}$ \\
\hline \multirow[t]{2}{*}{$\begin{array}{l}\text { Urrutia Blondel, } \\
\text { Jorge }\end{array}$} & $\begin{array}{l}\text { Ayer jui, y hoy no soy naiden } \\
\text { (tradicional chileno). }\end{array}$ & $11 / 05 / 2011$ & $\begin{array}{l}\text { Sala de Conciertos, } \\
\text { Universidad de Tula, Tula, } \\
\text { Rusia. }\end{array}$ & Dúo Álvarez-Henríquez. \\
\hline & & $13 / 05 / 2011$ & $\begin{array}{l}\text { IX Festival de Música } \\
\text { Universo del Sonido. } \\
\text { Cantos de Chile, un relato } \\
\text { bicentenario en Europa, } \\
\text { Sala Rachmaninov } \\
\text { del Conservatorio } \\
\text { Tchaikovsky, Moscú. }\end{array}$ & Dúo Álvarez-Henríquez. \\
\hline
\end{tabular}




\begin{tabular}{|c|c|c|c|c|}
\hline $\begin{array}{l}\text { Nombre del } \\
\text { Compositor }\end{array}$ & Título de la obra & $\begin{array}{l}\text { Fecha de } \\
\text { Interpretación }\end{array}$ & Lugar & Intérpretes \\
\hline \multirow{2}{*}{\multicolumn{2}{|c|}{$\begin{array}{l}\text { Urrutia Blondel, } \\
\text { Jorge }\end{array}$}} & $14 / 05 / 2011$ & $\begin{array}{l}\text { Sala de Conciertos, } \\
\text { Universidad de Saoksky, } \\
\text { Saoksky, Rusia. }\end{array}$ & $\begin{array}{l}\text { Dúo Álvarez-Henríquez: } \\
\text { Ana Álvarez Kemp, soprano; } \\
\text { Patricio Henríquez Ulloa, } \\
\text { guitarra clásica. }\end{array}$ \\
\hline & & $15 / 05 / 2011$ & $\begin{array}{l}\text { Sala de Publicaciones, } \\
\text { Universidad de Saoksky, } \\
\text { Saoksky, Rusia. }\end{array}$ & Dúo Álvarez-Henríquez. \\
\hline
\end{tabular}

17/05/2011 Salón Filarmónico, Teatro Dúo Álvarez-Henríquez. Municipal de Tula, Tula, Rusia.

24/05/2011 Sala de Sesiones, División Dúo Álvarez-Henríquez. Euroasiática Organización Iglesia Adventista del 7mo. Día Chilena, Moscú.

$28 / 05 / 2011$

Vos sois la estrella más linda 11/05/2011 (tradicional chileno).

Teatro Moulin D'Ande, Centro Cultural Moulin

Dúo Álvarez-Henríquez. D'Ande,Normandie, Francia.

Sala de Conciertos, Universidad de Tula, Tula, Rusia.

$13 / 05 / 2011$

IX Festival de Música Universo del Sonido, Cantos de Chile, un relato bicentenario en Europa, Sala Rachmaninov del Conservatorio Tchaikovsky, Moscú.

14/05/2011 Sala de Conciertos, Dúo Álvarez-Henríquez. Universidad de Saoksky, Saoksky, Rusia.

15/05/2011 Sala de Publicaciones, Dúo Álvarez-Henríquez. Universidad de Saoksky, Saoksky, Rusia.

17/05/2011 Salón Filarmónico, Teatro Dúo Álvarez-Henríquez. Municipal de Tula, Tula, Rusia.

24/05/2011 Sala de Sesiones, División Dúo Álvarez-Henríquez. Euroasiática Organización Iglesia Adventista del 7mo. Día Chilena, Moscú.

28/05/2011 Teatro Moulin D’Ande, Dúo Álvarez-Henríquez. Centro Cultural Moulin D'Ande, Normandie, Francia. 


\begin{tabular}{|c|c|c|c|c|}
\hline $\begin{array}{l}\text { Nombre del } \\
\text { Compositor }\end{array}$ & Título de la obra & $\begin{array}{l}\text { Fecha de } \\
\text { Interpretación }\end{array}$ & Lugar & Intérpretes \\
\hline \multirow[t]{4}{*}{$\begin{array}{l}\text { Valenzuela, } \\
\text { Eduardo }\end{array}$} & $\begin{array}{l}\text { Tres miniaturas } \\
\text { (Improvisando liberamente, } \\
\text { Lento espressivo, Ostinato } \\
\text { comodo ed esaltato) (1984) } \\
\text { para violoncello solo. }\end{array}$ & $19 / 08 / 2011$ & $\begin{array}{l}\text { Ritornelo, Encuentro } \\
\text { Regional de Orquestas } \\
\text { Juveniles e Infantiles } \\
\text { del Biobío, Teatro } \\
\text { Universidad de } \\
\text { Concepción. }\end{array}$ & $\begin{array}{l}\text { Eduardo Valenzuela, } \\
\text { violoncello. }\end{array}$ \\
\hline & $\begin{array}{l}\text { Seis estudios sobre ritmos } \\
\text { latinoamericanos }\left(\mathrm{N}^{\circ} 1\right. \\
\text { Con ritmos cubanos, } \mathrm{N}^{\circ} 2 \\
\text { Cuequeando, } \mathrm{N}^{\circ} 4 \text { Como un } \\
\text { choro brasileño, } \mathrm{N}^{\circ} 6 \text { Como } \\
\text { una cantilena, } \mathrm{N}^{\circ} 7 \text { Como } \\
\text { un rock, } \mathrm{N}^{\circ} 8 \text { Como un } \\
\text { mambo) para violoncello } \\
\text { solo (2001-2002) }\end{array}$ & $19 / 08 / 2011$ & $\begin{array}{l}\text { Ritornelo, Encuentro } \\
\text { Regional de Orquestas } \\
\text { Juveniles e Infantiles } \\
\text { del Biobío, Teatro } \\
\text { Universidad de } \\
\text { Concepción. }\end{array}$ & $\begin{array}{l}\text { Eduardo Valenzuela, } \\
\text { violoncello. }\end{array}$ \\
\hline & $\begin{array}{l}\text { Celleando para } \\
\text { violoncello y dispositivo } \\
\text { electroacústico (2009). }\end{array}$ & $19 / 08 / 2011$ & $\begin{array}{l}\text { Ritornelo, Encuentro } \\
\text { Regional de Orquestas } \\
\text { Juveniles e Infantiles } \\
\text { del Biobío, Teatro } \\
\text { Universidad de } \\
\text { Concepción. }\end{array}$ & $\begin{array}{l}\text { Eduardo Valenzuela, } \\
\text { violoncello. }\end{array}$ \\
\hline & $\begin{array}{l}\text { Cinco estudios mixtos para } \\
\text { violoncello y dispositivo } \\
\text { electroacústico (2010). }\end{array}$ & $19 / 08 / 2011$ & $\begin{array}{l}\text { Ritornelo, Encuentro } \\
\text { Regional de Orquestas } \\
\text { Juveniles e Infantiles } \\
\text { del Biobío, Teatro } \\
\text { Universidad de } \\
\text { Concepción. }\end{array}$ & $\begin{array}{l}\text { Eduardo Valenzuela, } \\
\text { violoncello. }\end{array}$ \\
\hline $\begin{array}{l}\text { Vergara, Juan } \\
\text { Pablo }\end{array}$ & $\begin{array}{l}\text { Desfases }(2010) \text { para } \\
\text { orquesta. }\end{array}$ & $1,2 / 07 / 2011$ & $\begin{array}{l}\text { Teatro Universidad de } \\
\text { Chile. }\end{array}$ & $\begin{array}{l}\text { Camerata Vocal de la } \\
\text { Universidad de Chile, } \\
\text { Massimiliano Caldi, director } \\
\text { invitado. }\end{array}$ \\
\hline \multirow[t]{4}{*}{ Zamora, Carlos } & $\begin{array}{l}\text { *Andesina }(2011) \text { para } \\
\text { conjunto. }\end{array}$ & $22 / 05 / 2011$ & $\begin{array}{l}\text { Auditorio Universidad de } \\
\text { Los Andes, San Carlos de } \\
\text { Apoquindo, Santiago. }\end{array}$ & $\begin{array}{l}\text { Camerata Universidad de } \\
\text { los Andes, Eduardo Browne, } \\
\text { director titular. }\end{array}$ \\
\hline & $\begin{array}{l}\text { Turi }(2008) \text { para flauta y } \\
\text { guitarra. }\end{array}$ & $30 / 05 / 2011$ & $\begin{array}{l}\text { Universidad Academia de } \\
\text { Humanismo Cristiano, } \\
\text { Auditorio Salvador } \\
\text { Allende, Providencia. }\end{array}$ & $\begin{array}{l}\text { Dúo divertimento: } \\
\text { Carmen Troncoso, flauta y } \\
\text { Luis Castro, guitarra. }\end{array}$ \\
\hline & $\begin{array}{l}\text { Misa brevis (2010) para } \\
\text { orquesta y coro. }\end{array}$ & 06/08/2011 & $\begin{array}{l}\text { Teatro Universidad de } \\
\text { Concepción. }\end{array}$ & $\begin{array}{l}\text { Orquesta Sinfónica y Coro de } \\
\text { la Universidad de Concepción, } \\
\text { Carlos Zamora, director. }\end{array}$ \\
\hline & $\begin{array}{l}\text { *Pieza de concierto sobre } \\
\text { temas de Vaughan Williams } \\
\text { (2011) para orquesta de } \\
\text { cámara. }\end{array}$ & $27 / 09 / 2011$ & $\begin{array}{l}\text { Aula Magna Universidad } \\
\text { Austral de Chile. }\end{array}$ & $\begin{array}{l}\text { Orquesta de Cámara de } \\
\text { Valdivia, Pedro Pablo } \\
\text { Prudencio, director invitado. }\end{array}$ \\
\hline
\end{tabular}


Cuadro sinóptico de música para cine de compositores nacionales interpretada durante el primer semestre 2010

\begin{tabular}{|c|c|c|c|c|c|}
\hline $\begin{array}{l}\text { Nombre del } \\
\text { compositor }\end{array}$ & Película & $\begin{array}{l}\text { Nombre } \\
\text { director }\end{array}$ & $\begin{array}{l}\text { Fecha de } \\
\text { estreno }\end{array}$ & Lugar & Intérpretes \\
\hline $\begin{array}{l}\text { Parra, Violeta/ } \\
\text { Parra, Ángel }\end{array}$ & $\begin{array}{l}\text { Violeta se fue a los } \\
\text { cielos (2011). }\end{array}$ & $\begin{array}{l}\text { Andrés Wood, } \\
\text { director. } \\
\text { Francisca } \\
\text { Gavilán } \\
\text { (Violeta) }\end{array}$ & $11 / 08 / 2011$ & $\begin{array}{l}\text { Santiago: } \\
\text { Cines Hoyts } \\
\text { de La Reina, } \\
\text { Estación } \\
\text { Central, Parque } \\
\text { Arauco, Puente } \\
\text { Alto y Arauco } \\
\text { Maipú; } \\
\text { Quillota : Cine } \\
\text { Paseo del Valle; } \\
\text { Quilpué: Cine } \\
\text { Mall. }\end{array}$ & $\begin{array}{l}\text { Banda Sonora: } \\
01 \text { ¿Qué edad tiene? } \\
02 \text { Gavilán. } \\
03 \text { Parabienes. } \\
04 \text { Qué pena siente el alma. } \\
05 \text { El palomo. } \\
06 \text { Arriba quemando el sol. } \\
07 \text { ¿Usted es comunista? } \\
08 \text { Dejo botá mi nación. } \\
09 \text { Jardines humanos. } \\
10 \text { Canción del angelito. } \\
11 \text { Rin del angelito. } \\
12 \text { ¿Qué pasa si nos } \\
\text { encontramos? } \\
13 \text { El joven Sergio. } \\
14 \text { Volver a los } 17 . \\
15 \text { Eso no se avisa. } \\
16 \text { Run run. } \\
17 \text { Te fuiste chinito. } \\
18 \text { Maldito del alto cielo. } \\
19 \text { La creación. } \\
20 \text { El gavilán. } \\
21 \text { La vida es más grande. } \\
22 \text { Violeta se fue a los cielos. }\end{array}$ \\
\hline
\end{tabular}

